\title{
Communicative Functions in Human-Computer Interface Design: A Taxonomy of Functional Animation
}

\author{
Raquel Avila-Munoz \\ raquelav@ucm.es \\ Maria Jose Perez-Luque \\ ESNE, Spain \\ marijose.perezluque@esne.es
}

Jorge Clemente-Mediavilla

Complutense University of Madrid, Spain Complutense University of Madrid, Spain

jclemen@ucm.es

\begin{abstract}
Whenever a user performs a task or communicates via their computer or device, they are guided by visual cues to interact successfully with the interface. This human-computer interaction is, therefore, mediated by the communication established between designer and user through the texts, graphic elements, and animations that make up the visual design of the interface. Animation is an element of visual language of the graphical elements of an interface. This study aims to establish the functions of animation. We reviewed the literature and discussed the shortcomings identified in the existing taxonomies of functional animation. We then proposed an updated classification, partly inspired by the functions presented in Jakobson's communication model. Based on a content analysis of the design guidelines from the leading mobile phone developers and comparing these sources, we propose the following list of categories: Identifying, Structural, Guide, Feedback, Didactic, Esthetic, and Emotive. This new taxonomy aims to contribute to the theoretical frameworks used in visual communication when studying interface design. It will be useful, for example, to help detect, classify, and assess the appropriateness of animations based on the functions they provide to an interface.
\end{abstract}

\section{Highlights}

- The literature review highlights the importance of considering the application scope when classifying the animation functions used in interface design.

- The review of the existing taxonomies of animated functions demonstrates the need to propose an updated classification.

- Jakobson's communication model is analyzed from the viewpoint of applying visual communication to interface design.

- A content analysis of iOS and Android design guidelines extracted the main animation functions used in mobile device interfaces.

- We propose a new taxonomy of functional animation to improve usability and user experience when using animation in interface design.

Suggested citation: Avila-Munoz, R., Clemente-Mediavilla, J. \& Perez-Luque, M. J. (2021). Communicative Functions in Human-Computer Interface Design: A Taxonomy of Functional Animation. Review of Communication Research, 9. 119-146. https://doi.org/10.12840/ISSN.2255-4165.030

Keywords: animation, motion design, user experience, user interface design, visual design.

Editor: Giorgio P. De Marchis (Complutense University of Madrid, Spain).

Reviewers who acceepted to sign their review: Enrique Castello Mayo (Universidad de Santiago de Compostela, Spain); a second reviewer prefers to stay anonymous.

Received: Sep. $2^{\text {th }} 2020$

Accepted: Mar. 21 2021

Prepublished: Abr. 2021

Published: June 2021 


\section{Content}

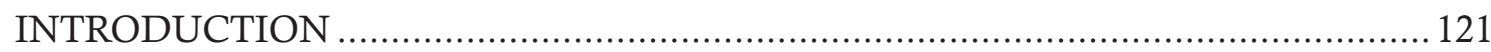

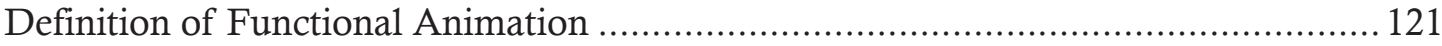

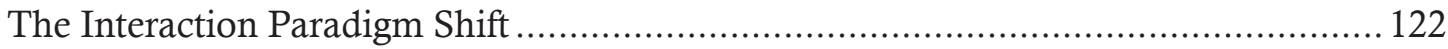

Taxonomies and Terminology According to the Scope of Application ....................... 122

Literature Search Strategies and Other Sources.................................................... 123

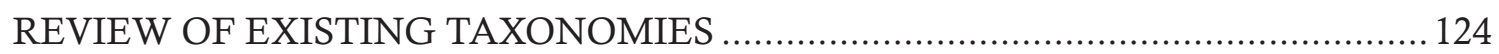

Categories in Baecker and Small's Initial Classification............................................... 124

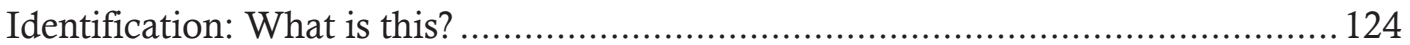

Transition: From Where Have I Come, To Where Have I Gone?.......................... 125

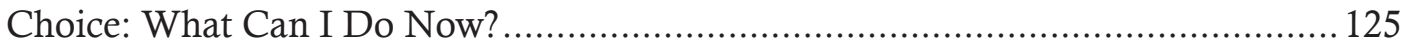

Demonstration: What Can I Do With This? ..................................................... 125

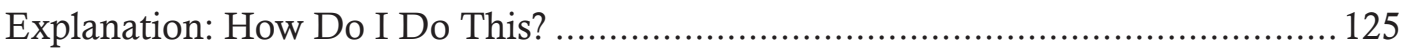

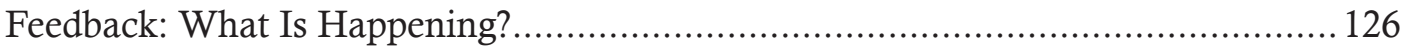

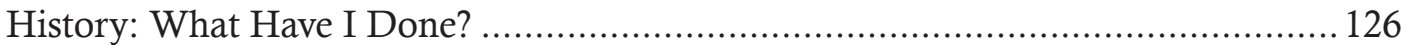

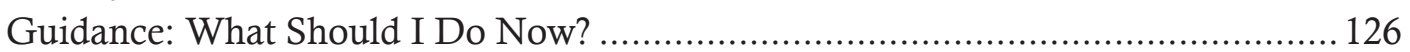

Subsequent Incorporation of Categories by Baecker et al...................................... 126

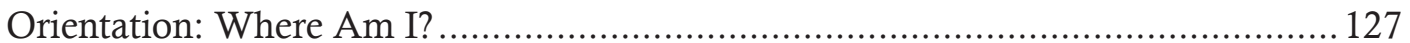

Interpretation: Why Did That Happen?............................................................ 127

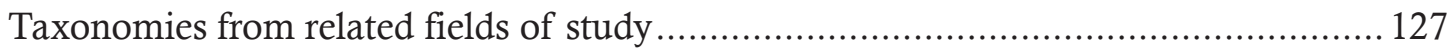

Specific taxonomies for the field of user interface design....................................... 129

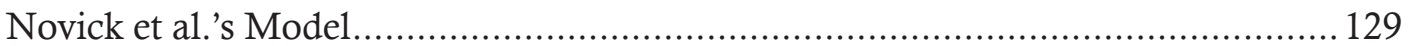

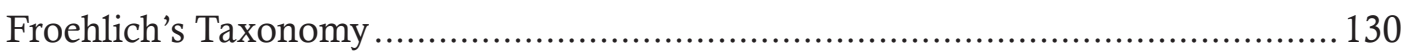

Functional Animation in Nonacademic Sources.............................................. 130

Thematic Analysis of Design Guidelines................................................................. 132

PROPOSAL AND ELABORATION OF A NEW FUNCTIONAL ANIMATION

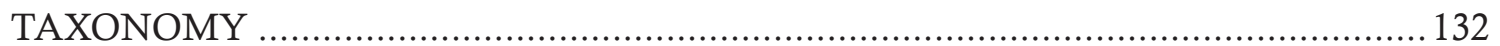

The Jakobson Model and Designer-User Communication.................................... 132

Functions in Jakobson's Communication Model .................................................. 132

Connections to Design Principles and Guidelines................................................ 132

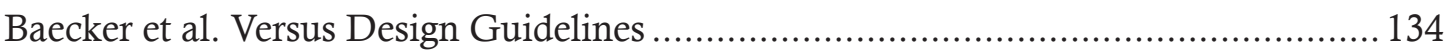

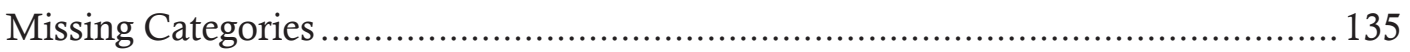

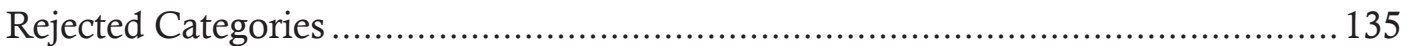

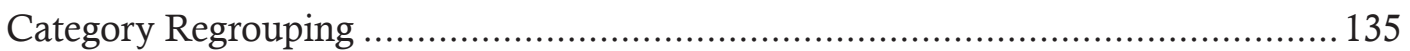

Categories in the New Functional Animation Taxonomy …................................... 136

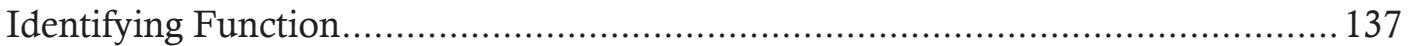

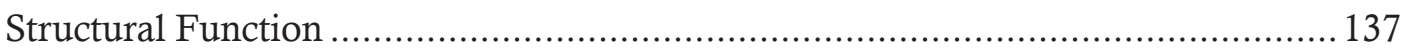

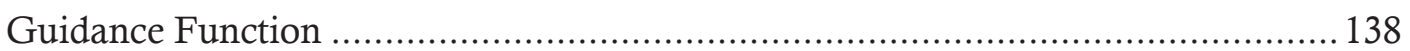

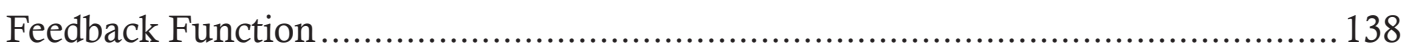

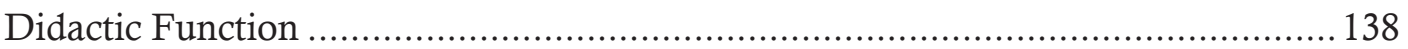

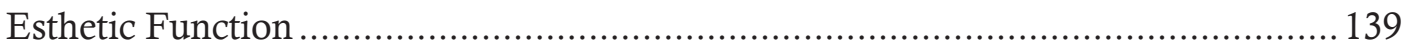

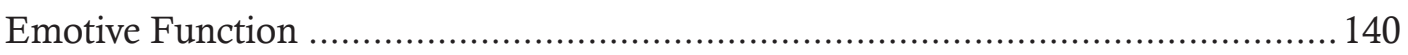

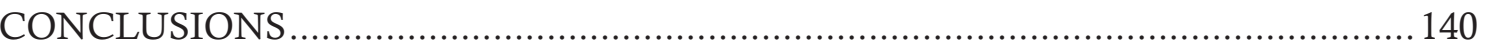

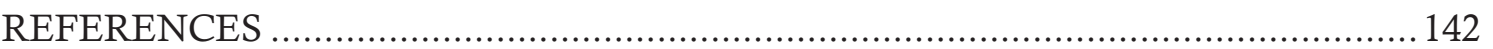

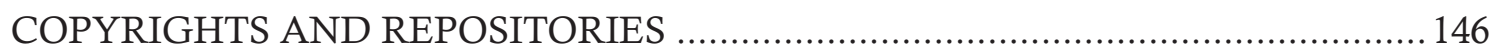




\section{Introduction}

One of the most frequent definitions of the term "interface" describes it as the means by which users and computers communicate (Scolari, 2018; Walker, 1990). From a semiotic perspective, visual cues-such as text, and static and dynamic signs provided by the interface designer-ensure that communication is effective (de Souza et al., 2010). Thus, communication is an essentially visual communication route between the interface designer and user. All dynamic signs rely on animation, which is defined as any change in the graphical representation of an element over time (Stasko, 1990).

In establishing the discipline of interface design, Baecker and Small (1990) collated the vast potentialities of animation as an interface design tool. The authors pointed out that animation was already commonly used within program visualization or three-dimensional computer graphics, and highlighted "animation of function" as a novel field of study. Animation of function is the use of animation in interface elements themselves with the purpose of making the interface more understandable, and it has not to be confounded with the animated content viewed through an interface. Baecker and Small's classification, developed in a period of high interest in graphical user interface design, is based on the incipient graphical uses of the time and was complemented by an outline of new ideas that could enrich the future of interface design. The authors even described some concepts that were not technically possible at the time of their writing. They considered that the uses of animation have "barely scratched the surface of what is possible and interesting" (Baecker \& Small, 1990, p. 251), and it has been confirmed since the mid-1990s and reflected in the growing use of animations both online and in interactive multimedia programs.

Baecker and Small's taxonomy was updated a few years ago by Chevalier et al. (2016). However, the review has been approached from the information visualization perspective rather than interface design. Therefore, Chevalier et al.'s update is not enterely appropriate to classify animation's potential uses in the specific area of user interface design. The present article analyzes the revised taxonomy critically and creates a proposal specifically adapted to interface design. In particular, animation, along with other visual elements, should help the user understand the operation of the system's interface and allow its use efficiently, thus providing a satisfactory user experience.

It is relevant to determine whether or not animation fulfills a relevant function in interface design because usability problems resulting from its inappropriate use have repeatedly been denounced by experts (Loranger et al., 2013; Nielsen, 1995, 2005). Superfluous animation that does not fulfill any particular function wastes system resources and can also negatively affect usability and user experience.

\section{Definition of Functional Animation}

As pointed out by the authors of Art of Human-Computer Interface Design, a seminal publication in the discipline, "we need to develop our understanding of how we perceive motion, what meanings we attribute to it, and how animation can have a more integral role in achieving interface goals" (Nicol, 1990, p. 120). We thus begin by specifying what we mean by functional animation.

In agreement with Stasko (1990), we consider functional animation as any visual change intentionally included in the design of an interface with the ultimate aim of improving its usability and the user experience. This approach has two essential characteristics mentioned in Liddle's (2016) definition: a) intentionality, which indicates the importance of the decisions made by the designer and excludes animations caused by errors or system failures, and $b$ ) a focus on visual rather than graphical changes in the representation of the elements. This subtlety is relevant since it allows to include the organization and composition of light indicators under the term "animation," a feature used in many devices without a graphical interface. This is the case of the elaborate light animations developed by Djajadiningrat et al. (2009) in the EmoBracelet and EmoBowl, or the physical movements of interface elements in various prototypes presented in DesForm (Spallazzo et al., 2019).

Liddle omits some particular animation types from his definition, such as the help animations and the animated introductions, considering them not to form part of the interface itself. However, unlike Liddle, we include them as part of the interface. In both help animations and animated introductions, the content and visual style--and even the inclusion of the animation itself,--are deliberate design decisions made to inform the user about the characteristics of the application, and thus facilitate the human-computer communication process. Indeed, these types of animations are used in several of the scenarios described in Baecker and 
Small's taxonomy. We exclude animations that are solely featured as content that the user views or shares through their device, for example, in the case of an animated gif created or downloaded by the user and used in a messaging application, or viewing an animated short film through an application such as YouTube. These cases cannot be considered to be functional animation.

When defining animation, some authors debate whether to consider interactivity as a necessary requirement (Bétrancourt \& Tversky, 2000; Gonzalez, 1996). However, this debate is not crucial when it comes to specifying the definition of functional animation here. For example, the inclusion of a decorative background animation without any interactive properties is a design decision that fulfills an esthetic function and could produce a relaxing effect on the user, thus improving their experience.

\section{The Interaction Paradigm Shift}

The technological advances of the last decades have made viable some of the propositions put forward in the 1990 taxonomy. However, the changes within the WIMP interaction paradigm have led to the ubiquitous use of mobile technology (Wasserman, 2010), thus making certain input devices, such as keyboards and mice, inappropriate for use in natural user interfaces (NUIs), where interaction is based on touch, speech, gestures, handwriting, and vision.

The distinctive features of NUIs have greatly influenced interface design. The omnipresence of smartphones has resulted in a prevailing "mobile first" design trend (Wroblewski, 2011) which prioritizes mobile interface design aiming for a satisfactory user experience, regardless of which device is used to access an application or browse online.

The main differences of the WIMP interaction paradigm with respect to interactions with smartphones are related to the input device, context of use (López-Jaquero et al., 2020), and screen size. The desktop computer user has two precise input devices: the mouse, for differentiating between graphical elements the size of a pixel (Wigdor \& Wixon, 2011, p. 73 ), and the keyboard, the fastest and most accurate textinput device (Shneiderman et al., 2018, p. 340). For mobile phones, our fingers are the pointing devices, and often we use our thumbs, which sometimes make it difficult to access certain areas of the screen and limiting our precision of movement (Parhi et al., 2006). Our fingers condition the arrangement of the interactive elements on screen, whose reduced dimensions further limit the potential number and size of the elements. Mobile phone devices are normally used in multitasking environments: walking, standing up on public transport, or even during sports (Y. Li et al., 2020; Marshall et al., 2016). Distraction and interaction in motion make it difficult to interact with the device, resulting in input errors.

As graphic design and navigation must adapt to the characteristics of each paradigm (Wigdor \& Wixon, 2011), the same can be said for the use of animation. Therefore, Baecker and Small's 1990 taxonomy of functions must be reviewed in light of the new paradigm.

\section{Taxonomies and Terminology According to the Scope of Application}

After Baecker and Small's proposal, various similar attempts have focused on different uses of animation in the interface, mainly in the field of information visualization. Among these, the proposal by Chevalier et al. (2016) stands out for its academic approach. Despite proposing a general taxonomy, the authors concentrated on their specific research field, as indicated in their methodology chapter: "we surveyed animation examples we were most familiar with: the domain of information visualization" (Chevalier et al., 2016, p. 280).

The information visualization field focuses on the graphical representation of data and concepts to facilitate its understanding (Ware, 2020). By using bar graphs, flowcharts, point distribution maps, or other visual representations, abstract information is presented in a way that enables large amounts of data to be synthesized, shows connections between elements, and facilitates the interpretation of complex concepts. Visual representation of abstract information is present in both print and audiovisual media, as well as computer applications and online, although the user does not always interact with the interface of such products. Sometimes, the user is a passive spectator, for example, when watching a presentation that explains a country's demographic evolution over time using slides (e.g., PowerPoint, Prezi) or an explanatory video. Although an interface may sometimes be interactive, such animated graphical elements' primary objective is to explain the information content, and not necessarily to explain the interface or how to interact with it to access the content.

In her doctoral thesis, Chalbi (2018) explains the steps 
followed to clarify and validate Chevalier et al. (2016)'s taxonomy. Moreover, she presents a literature search of the ACM digital library database and keyvis.org limited to the keywords "animation" and "animated transition." In the English-language literature on interface design, the term "animation" is rare, while the terms "motion" and "movement" are more common, as observed by Liddle (2016). This leads us to suggest that the literature identified by the authors may lack some relevant references. For example, the term "animation" does not appear in the keywords of De la TorreArenas and Cruz's (2017) proposed taxonomy, and is scarcely used throughout their text.

The results of an updated literature review are presented here to determine whether the search carried out by Chevalier et al. missed any relevant references as a result of their limitation to the terms "animation" and "animated transition." Thereafter, having confirmed that no recent taxonomies in the field of interface design include a methodology accounting for the described change in interaction paradigm, we develop a proposal for a taxonomy of functional animation.

\section{Literature Search Strategies and Other Sources}

For the literature review, we searched the Web of Science, SCOPUS, and Google Scholar databases, as well as the ACM digital library, which is, undoubtedly, the benchmark database in the sector. Here we explain the search run on the ACM digital library, as the searches in other databases did not extend the results. We began with a search for publications including the terms "animation," "motion," "transition," and "microinteraction," and possible derivatives (e.g., "animate," "animated transitions," and "microinteractions"), as well as "taxonomy" in the title. Only 2 of the 13 search results were relevant: the works of De la Torre-Arenas and Cruz (2017) and Froehlich et al. (2013). Some of the found papers presented animation taxonomies, but not applied to interface design, such as a taxonomy related to moving robots, and they were therefore discarded. Due to the omission of the work by Chevalier et al., we repeated the search, but now limited to the keywords defined by the authors. This second search identified the key article, but excluded other relevant references present in their bibliography. We thus expanded the search to include the abstract, then yielding a total of 468 articles, of which 20 were related to our study topic. This result is due to the wide use of the search terms, particularly in areas such as robotics, video games, or virtual reality.

The failure to identify relevant authors, such as Bartram, led us to review our strategy, tracing the sources of key articles and following up the authors who cite them in detail, as well as activating an alert in ACM and Google Scholar to inform us of new, relevant articles.

In addition to the literature review, it is valuable for the development of the taxonomy to study the actual uses of functional animation. A possible approach would be to define and analyze a sample from actual products. Another option is to analyze recommended uses in the design guidelines of the main developers. We have chosen to follow the latter procedure.

Apple's design guidelines (1987), developed for the release of the Macintosh, have long been cited as a key source to guide professionals when defining a design language (Rheinfrank \& Evenson, 1996). As reported by Shneiderman et al. (2018), various guidelines for online and mobile devices have been developed over time, based on practice, experience, and empirical studies. Wasserman (2010) confirms that professionals follow the set of recommended best practices and examples in the design guidelines of the main developers. With this in mind, we propose an analysis of Apple's content (Apple Inc., n.d.) and Android's (Google, n.d.) guidelines to identify appropriate uses of animation for correct application development. The specific details of this procedure are mentioned later in order to present the results in a precise manner.

To develop our taxonomy proposal, we seek for inspiration in Jakobson's communication model and its functions of language. We have considered Jakobson's model to represent a good effort to define the role played by animation in the visual language that designers employ to communicate with users. Since the ultimate goal of interface design is to improve the usability and user experience, we sought connections between Jakobson's approach and the key concepts of NUI interfaces as reflected in the fundamental principles of interaction design described by Norman and Nielsen (2010), Shneiderman's eight golden rules of interface design (Shneiderman, 1987; Shneiderman et al., 2018), Nielsen's (1994) heuristic evaluation principles, the principles defined by Stasko (1993) to guide the use of animations in interface design, and those subsequently collected by Saffer (2013).

Therefore, we developed our proposal for a new taxonomy after analyzing the literature critically. Taking as a start- 
ing point Baecker and Small's classification, and based on the parallels and shortcomings identified in the literature, we propose a new taxonomy. We consider that this new taxonomy represents the most relevant contribution of this paper to the field of interface design.

\section{Review of existing taxonomies}

\section{Categories in Baecker and Small's Initial Classification}

Categorized as "informal" by Chang and Ungar (1993, p. 46), Baecker and Small's (1990) classification establishes three main categories, in which animation plays a series of distinctive roles. The first role, "animation of structure," includes the various ways of representing complex systems through the visualization of an object and its environment, exploring its appearance from different points of view or under different lighting conditions. For example, computeraided design (CAD) or computer-aided manufacture (CAM) can be used to stimulate dangerous or difficult-to-access activities, which enable the evaluation of different scenarios. The second role, "animation of process," refers to the visualization of algorithms and programs. The authors present Sorting Out Sorting as an example. It is a 30-minutes animated film illustrating different sorting algorithms, made in 1981 by Roland Baecker (1998) with Dave Sherman's help. The third role, "animation of function," includes the uses of animation that make an interface more understandable for the user. Its eight categories answer a series of questions that animation can help to solve:

\section{Identification: What is this?}

This category includes the animations already present in video games of the time, which used animated introductions during the loading of the program to inform the user that the application has been started. Baecker and Small (1990) refer as an example the animated preview of Robot Odyssey 1, a game created in 1984 by The Learning Company (see Figure $1)$.

Figure 1. Example of Identification
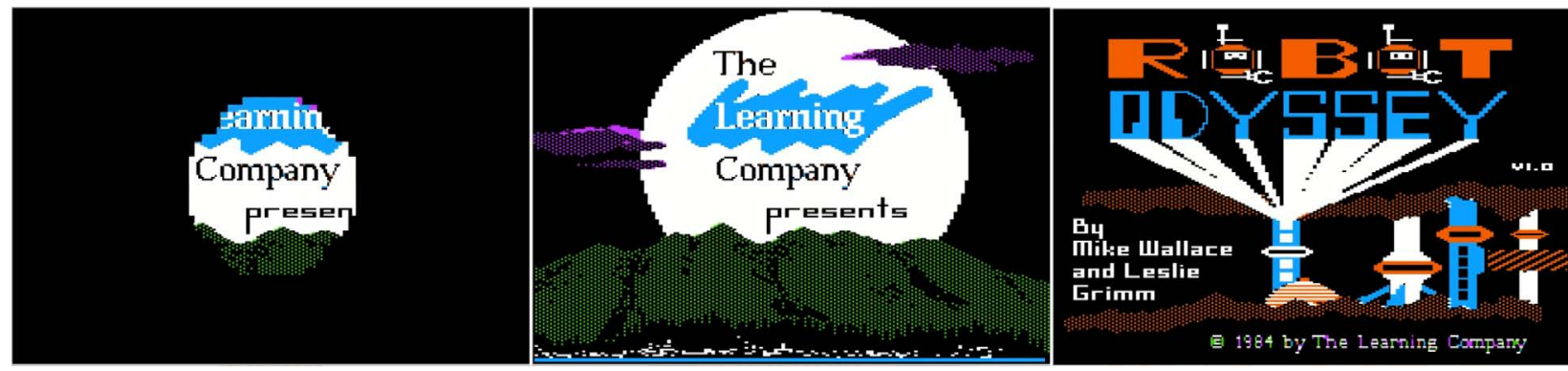

Note. Screenshots of Robot Odyssey 1 animated introduction from the game's video-capture by shodan1138 (2015). Copyright 1984 by The Learning Company.

Figure 2. Example of Transition (back to text)
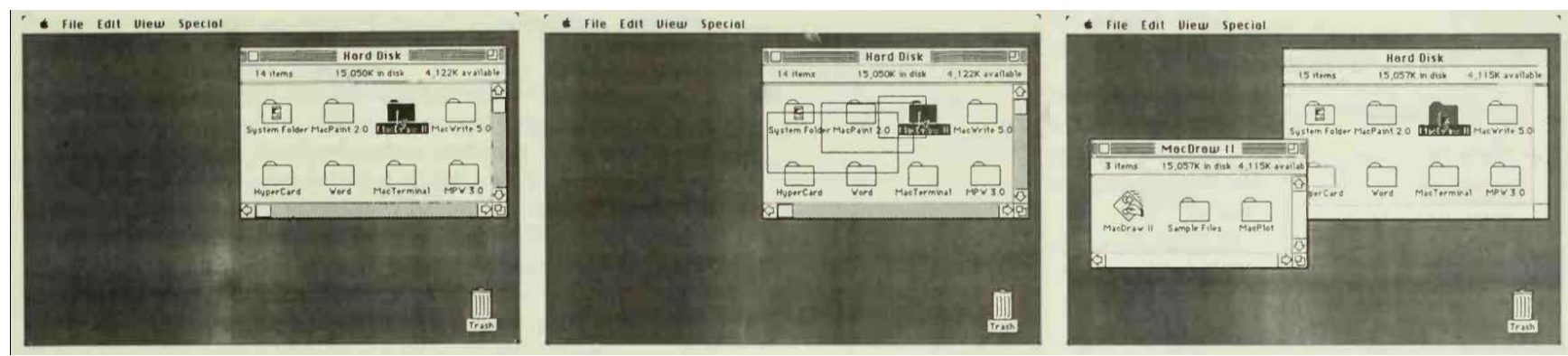

Note. Opening a new folder in Macintosh, taken from Baecker, R., \& Small, I. (1990). Animation at the Interface. In B. Laurel \& S. J. Mountford (Eds.), The Art of Human-Computer Interface Design (pp. 251-267). Addison-Wesley Publishing Co., Inc. Copyright 1990 by Apple Computer, Inc. 


\section{Figure 3. Example of Choice}
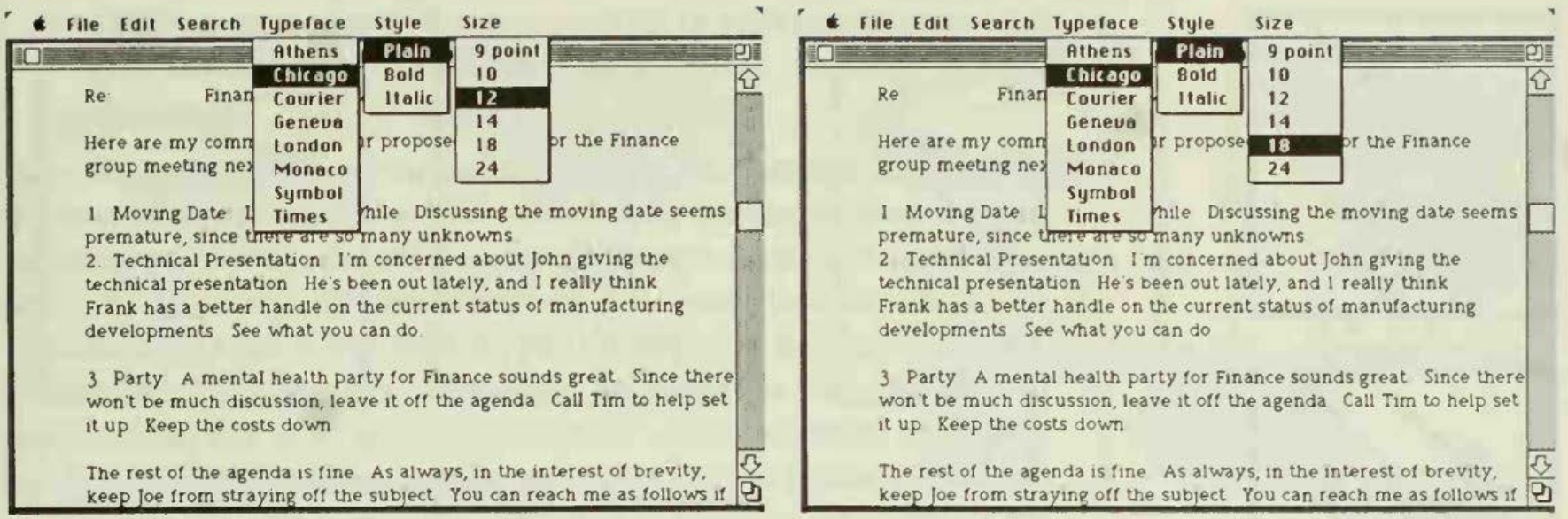

Note. Taken from Baecker, R., \& Small, I. (1990). Animation at the Interface. In B. Laurel \& S. J. Mountford (Eds.), The Art of HumanComputer Interface Design (pp. 251-267). Addison-Wesley Publishing Co., Inc. Copyright 1990 by Apple Computer, Inc.

Transition: From Where Have I Come, To Where Have I Gone?

These animations are intended to guide the user during the transition from one process to another. An example would be the animation of the outline as a new window opens on early Macintosh, directing the user's attention to where the new content will appear, as shown in Figure 2.

\section{Choice: What Can I Do Now?}

This enables all the options within a complex menu to be previewed. Although the technology of the time allowed this

\section{Figure 4. Example of Demonstration}
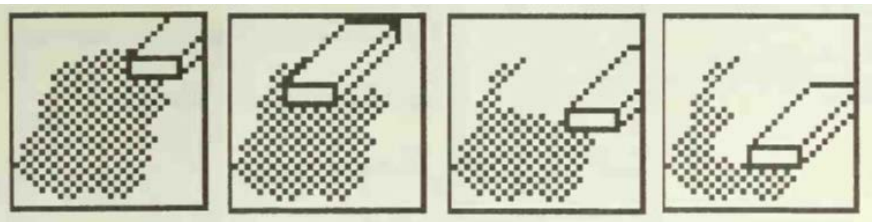

Note. Animation of the eraser icon in a paint program, taken from Baecker, R., \& Small, I. (1990). Animation at the Interface. In B. Laurel \& S. J. Mountford (Eds.), The Art of Human-Computer Interface Design (pp. 251-267). Addison-Wesley Publishing Co., Inc. Copyright 1990 by Apple Computer, Inc. type of development, the authors point out the need to verify the effectiveness of this approach and provide, as an example, the images presented in Figure 3, describing an animated menu set of choices.

\section{Demonstration: What Can I Do With This?}

The authors indicate that this concept is similar to that of identification, proposing that animations of icons can be used to provide further information about their function. They illustrate the concept with the example reproduced in Figure 4. The authors again point out the need to check whether this would be an effective use of animation due to the system resources required as well as to the possible perceptual and cognitive implications, particularly if several icons are animated at once.

\section{Explanation: How Do I Do This?}

In this case, the authors explicitly refer to tutorials that include animations to help explain an action, such as how to copy and paste.

The difference with respect to the previous role would be that the animation as a demonstration would be limited to informing about the functionality, in contrast the animation as an explanation would offer a detailed tutorial illustrating an action. This latter use was not applied at that time, since it would be necessary to develop tools to generate this type 
Figure 5. Example of Explanation

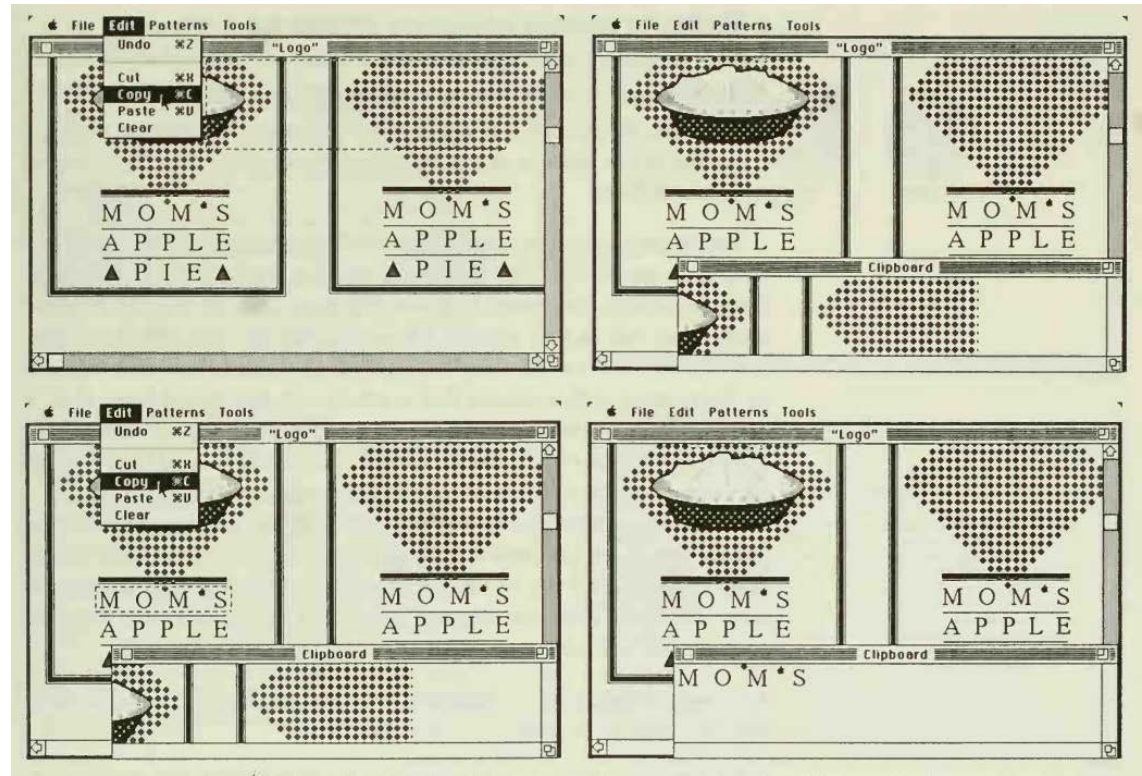

Note. Animated tutorial of the process of copy and paste and the use of the Clipboard in the Macintosh. Taken from Baecker, R., \& Small, I. (1990). Animation at the Interface. In B. Laurel \& S. J. Mountford (Eds.), The Art of Human-Computer Interface Design (pp. 251-267). Addison-Wesley Publishing Co., Inc. Copyright 1990 by Apple Computer, Inc.

of animations. Nevertheless, the authors include an example taken from Myers (1984), shown in Figure 5.

\section{Feedback: What Is Happening?}

Feedback animation provides up-to-date information on the status and active processes of the system. The authors describe the process indicators designed by Myers $(1985 ; 1984)$ for the Sapphire window manager used in the Perq stations (see Figure 6).

\section{History: What Have I Done?}

For this category, the authors present a hypothetical case, explaining that, at the time, it would not have been feasible even on scientific computers because hard disks with high storage capacity were required. It focuses on reproducing, through animation, an activity carried out by the user during an interaction. The goal would be to help the user understand where they are in an application and how they got there. Figure 7 shows the example provided by the authors.

\section{Guidance: What Should I Do Now?}

The objective of this role is to improve error messages through animation, making them more informative and less intimidating, thus helping users correct any errors quickly.
The authors raise the possibility that the system could provide instructions automatically, requiring artificial intelligence techniques that were not available at that time. Figure 8 reproduces the example provided by the authors.

\section{Subsequent Incorporation of Categories by Baecker et al.}

Baecker et al. (1991) expanded their classification with the addition of the categories Orientation and Interpretation,

Figure 6. Example of Feedback

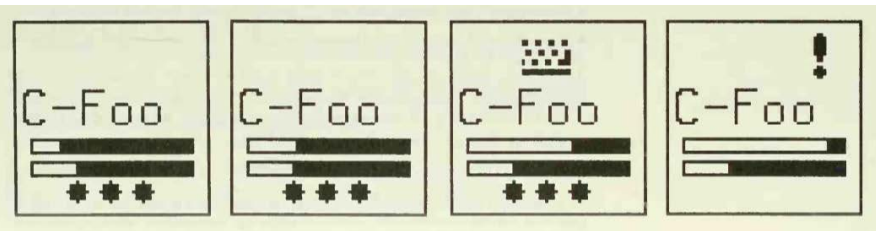

Note. Animated icon providing feedback in Sapphire. Taken from Baecker, R., \& Small, I. (1990). Animation at the Interface. In B. Laurel \& S. J. Mountford (Eds.), The Art of Human-Computer Interface Design (pp. 251-267). Addison-Wesley Publishing Co., Inc. Copyright 1990 by Apple Computer, Inc. 
Figure 7. Example of History (back to text)

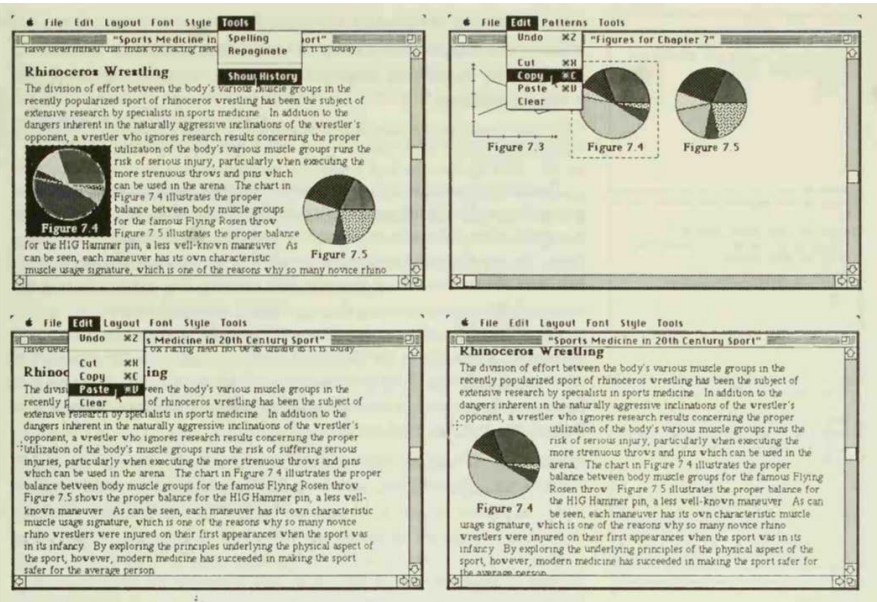

Note. The images represent an animated history of a copy and paste process. Taken from Baecker, R., \& Small, I. (1990). Animation at the Interface. In B. Laurel \& S. J. Mountford (Eds.), The Art of Human-Computer Interface Design (pp. 251-267). Addison-Wesley Publishing Co., Inc. Copyright 1990 by Apple Computer, Inc.

although little information was offered to justify this incorporation. Baecker continues to use the 1991 version in his later work (Baecker, 2002).

\section{Orientation: Where Am I?}

To illustrate this category, the same phrase was used as in Baecker and Small's explanation of the Transition category: "The outline zoom (an animated transition) which accompanies the opening (and closing) of an icon on many desktops orients the user to the location of the new window which appears on the desktop" (Baecker et al., 1991, p. 444).

\section{Interpretation: Why Did That Happen?}

The authors indicate that this category should answer the question "Why did that happen?" without providing any examples or description.

\section{Taxonomies from related fields of study}

Chevalier et al. (2016) started from the initial taxonomy of Baecker and Small (1990), considering it to be the most recent general classification of the roles of interface animation. Their objective was to update and expand the previous set of functions to stimulate research and identify new uses for animation.
Figure 8. Example of Guidance (back to text)

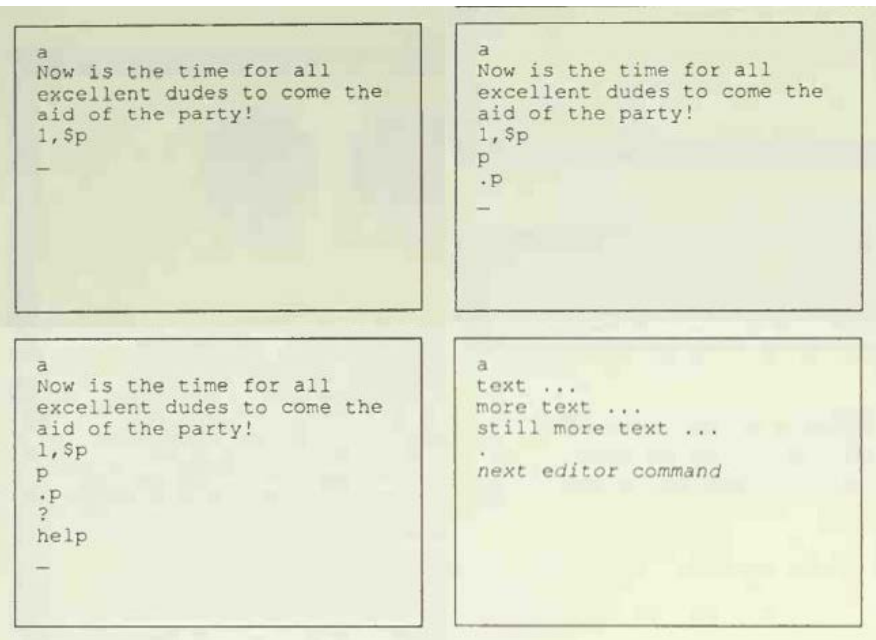

Note. The images represent an animated text providing guidance to the user. Taken from Baecker, R., \& Small, I. (1990). Animation at the Interface. In B. Laurel \& S. J. Mountford (Eds.), The Art of Human-Computer Interface Design (pp. 251-267). Addison-Wesley Publishing Co., Inc. Copyright 1990 by Apple Computer, Inc.

In order to prepare their proposal, Chevalier et al. reviewed the classifications established by other authors, such as Heer and Robertson (2007) and Fisher (2010), all focusing on the use of animation to support transitions between different views or states in data visualizations. They criticize the work of Heer and Shneiderman (2012), a taxonomy of possible dynamic interactions focused on the visual analysis of elements, by arguing that their classification does not explicitly delve into the functions of animation. In fact, Heer's and Shneiderman's classification includes tasks such as selecting and filtering data, classifying elements, or coordinating views for visual information analysis.

Then, Chevalier et al. highlight the work of Bartram (1997b). They consider it to be the only attempt, after Baecker and Small, to discuss the new roles of animation, although they point out that the author focused only on the data visualization field. However, this is not so. In her doctoral thesis, Bartram (2001) collects and expands on the subjects presented in her technical report (Bartram, 1997a). She starts from Baecker and Small (1990), then analyzes Harrington et al. (1994)'s classification, which she qualifies as intriguing and highly speculative, based loosely on theories of perception and applied experience. Bartram highlights how Harrington et al.'s proposal constitutes one of the first attempts to consider motion as an information display modality in its 
Figure 9. Example of an animation representing uncertainty or randomness
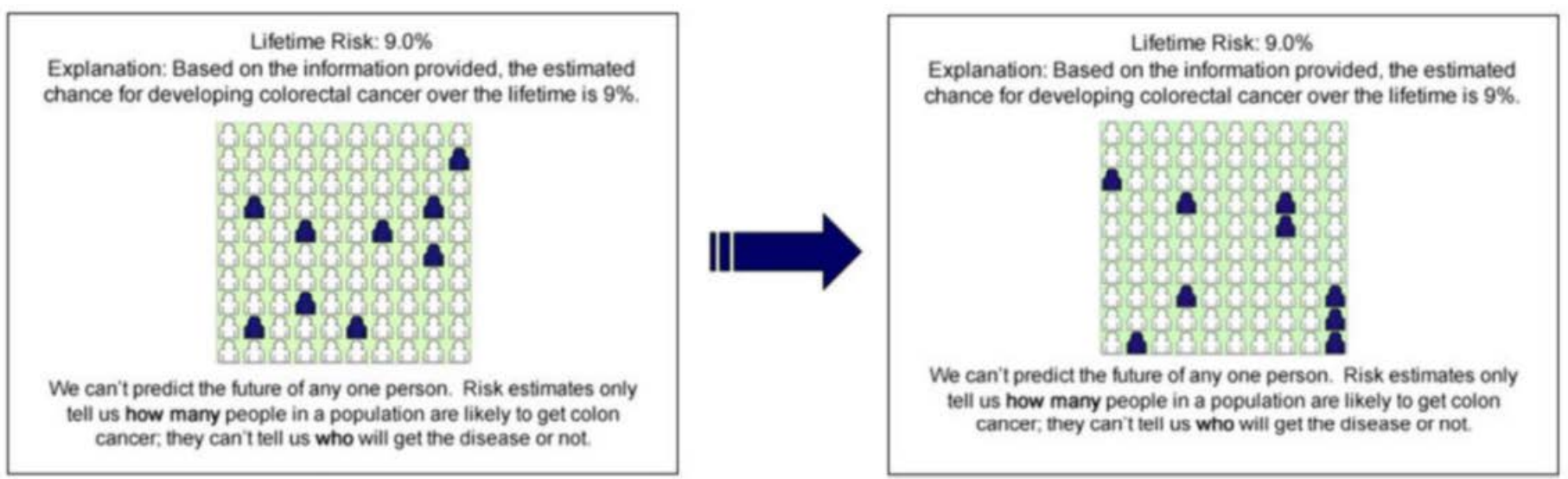

Note. Taken from Han, P. K. J., Klein, W. M. P., Killam, B., Lehman, T., Massett, H., \& Freedman, A. N. (2012). Representing randomness in the communication of individualized cancer risk estimates: Effects on cancer risk perceptions, worry, and subjective uncertainty about risk. Patient Education and Counseling, 86(1), 106-113. https://doi.org/10.1016/j.pec.2011.01.033

own right (Bartram, 2001, p. 35).

Despite not appearing in the list of bibliographic references, Chevalier et al. (2016)'s allusion to Bartram's technical report (1997a) would indicate that they also worked with this document. Moreover, Chevalier et al. cite a subsequent study in which the author participates (Bartram et al., 2003), indicating that they are familiar with their work. In any case, the authors collect the functions described by Bartram and include them in their taxonomy. The taxonomy of Chevalier et al. comprises a total of 23 roles organized into five categories: "keeping in context," "teaching aid," "user experience," "data coding," and "visual discourse."

The examples used to illustrate each function include numerous animation cases in the form of content displayed by the user through the interface, but not necessarily as part of it. Their classification lacks the distinction between animation as content and functional animation as included in Baecker and Small's taxonomy. This distinction is key to establishing which functions can animation perform as part of the visual language between the designer and user, allowing for more attractive and user-friendly interfaces.

On the other hand, there are many categories dedicated to specific situations that probably make sense when approaching the use of animation from the point of view of data visualization. However, that is not so evident when defining the visual configuration of a user interface. For example, they illustrate the function "transmit uncertainty or randomness" with the case of a visual presentation that reports on the percentage of chances of developing cancer through a panel made up of 100 icons. As shown in Figure 9, a certain number of these icons change color randomly, indicating that the percentage of possibilities is known, but not which specific individual will develop the disease.

Although the possibility of transmitting uncertainty may have a place in the user interface of a specific application, we wonder why not also include statements that refer to other states such as, for example, transmit frequency or security. Likewise, we wonder if this function, so specific as it is, could be included within the role "encode the attribute of an object." This role describes those cases in which animation can be used instead of color or shape to present the characteristics of the represented object or indicate that it belongs to a certain category. Similar alternatives could be proposed in other functions, such as the case of "persuade and convince," included in the category of visual discourse, which would lead us to wonder why it has not been considered to introduce the role "entertain," for example.

De la Torre-Arenas and Cruz (2017) proposed a taxonomy for the roles of motion in data visualization, focusing mainly on its communicative aspects. They consider Bartram's (2001) doctoral thesis as the most complete classification of its kind. Therefore, they begin with Bartram's eight categories (i.e., awareness, transition, functional description, emphasis, expression, representation of change, direct visualization, and association). Then, they select those relevant to their object of study and make their proposal focused on 
four communicative functions: portraying data, interpolating between data attributes, guiding viewers through the visualization, and attracting users' attention. Of these categories, the authors highlight the novel function interpolation between data attributes, which is also included in the classification of Chevalier et al.

In her doctoral thesis, Chalbi (2018) describes the method Chevalier et al. followed to develop their taxonomy and includes the works of Weiss et al. (2002) and Novick et al. (2011) in her list of revised taxonomies. Weiss et al.'s five functions (i.e., cosmetic, attention gaining, motivation, presentation, and clarification) focus on the field of computerbased instruction, thus analyzing animation as content with didactic objectives. Novick et al. is the only study to focus on user interface design, which is the scope of the current work. Their classification is relevant to Chalbi, although she considers that it covers only a fraction of all the possible animation functions.

Before analyzing the taxonomies specific to our area of interest, it should be noted that the proposal by Chevalier et al. is undoubtedly the most complete of those analyzed, as it includes all the categories present in the other taxonomies in the field of information visualization. It is also, as reflected in Chalbi's (2018) doctoral thesis, the only one that carries out a validation process.

Bartram differentiates the field of interface design from the field of information visualization when she explains how she has carried out a general examination in search of empirical studies that support the "strong intuition about the usefulness of movement to communicate" (Bartram, 2001, p. iii).

This approach of specifically citing both fields of study is related to that proposed by Chang and Ungar (1993) regarding the differences between the various application fields of animation. As explained above, this leads us to suggest that Chevalier et al.'s taxonomy may be a complete and useful tool to study animation in the field of information visualization. However, despite being proposed as a general taxonomy, it was developed with information visualization in mind. This fact is evidenced by the difficulty in differentiating between the categories that refer to animation as content and those that refer to functional animation, as well as the tendency towards extreme detail in some categories that are irrelevant outside the field of data visualization. Therefore, Chevalier et al.'s taxonomy could present shortcomings when used in other areas, such as the considered herein, design of user interfaces (Avila-Muñoz et al., 2019).

\section{Specific taxonomies for the field of user interface design}

After a search in the field of user interface design, the following two references should be highlighted: the enumeration of communicative functions outlined by Novick et al. (2011), and the inspiring proposal by Froehlich (2010) based on the description of phenomena that occur in nature.

\section{Novick et al.'s Model}

Novick et al.'s classification includes seven communicative functions that distinguish "signal different context," "signal different value," "signal different status," "signal importance, or urgency," "signal different function," "signal referent (pointing)," and "signal salience." Some of these concepts are not clearly defined, as observed by Liddle (2016). Note that Novick et al.'s approach is not intended as an elaboration of a taxonomy but rather as a model outline to link certain forms of animation, such as a change in the color of an element or variations in its size, orientation, and position, and their adequacy for achieving a certain communicative purpose. For example, according to their model, the most appropriate representation to indicate a change of state would be to vary the color of an element. Meanwhile, to indicate a change in value, it would be more effective to visualize it through an animation that modifies the size of the element; to indicate prominence, a blur effect would be more effective.

However, the authors do not offer any definition of the scope of the different communicative functions that they identified through an exploratory analysis of 60 sources with very diverse characteristics (e.g., operating systems, websites, games, and even prototypes). The authors point out the limitations of generalizing from their non-exhaustive selection of sources. They suggest the possibility of refining the categories in the future, considering their model as a starting point.

The lack of a definition for the categories, and even the terminology used, poses difficulties when using this taxonomy. A category that seeks to collect the uses of animation that "signal different" would exclude those indicating that there is no difference. This is the case for process indicators showing an animated loop used to communicate that the system is still busy. They do not "signal different status." Rather, this animation indicates that there is no difference, 
no change, in the status of the system state. In terms of Baecker et al.'s definition, interface animation can guide us within the structure of a system, it can provide feedback, or it can have a didactic function, such as demonstrating how to use an application. However, distinguishing "different values," or indicating the salience of a certain element, neither help understand the ultimate goal of the animation nor provide any useful information regarding whether it is fulfilling a relevant function in improving the system usability. The categories defined by Novick et al. make sense within their model, but do not represent an improvement over those established by Baecker and Small in classifying the general functions that animation can perform in relation to usability and user experience.

\section{Froehlich's Taxonomy}

Froehlich (2010) explores motion from different perspectives with the aim of understanding its fundamental qualities and applying them to interface design. Her conclusion is very similar to that of Baecker and Small. She then points out that her taxonomy is not exhaustive and that exploring the use of moving textures and patterns could offer new opportuni- ties (Froehlich et al., 2013). Her original classification, composed of the terms "show" (direct attention), "tell" (impart, express thoughts), "orient" (set context), "acquaint" (introduce, make familiar), and "warn" (give notice of danger), is expanded in Froehlich (2018) with the addition of the concept of "delight" (give a high degree of gratification, or pleasure). Despite the conceptual similarities between Froehlich 's categories and those of Baecker and Small, we consider the 1990 taxonomy to be more appropriate as a starting point because it includes particular concepts that are clearly aligned with the principles of interface design, specifically its terminology and definition, such as "feedback", a term that does not appear in Froehlich's classification.

Therefore, the literature review does not reveal any relevant taxonomies that add novel and significant features to the initial proposal by Baecker and Small, except for the addition of the term "delight" in Froehlich's classification.

\section{Functional Animation in Nonacademic Sources}

It should be noted that many authors cite some possible uses of animation without claiming to provide an exhaustive

Figure 10. Thematic blocks compiled by authors from the Android and Apple iOS design guidelines (back to text)

\section{Thematic blocks extracted from Android and Apple iOS design guidelines}

IDENTIFICATION AND INFORMATION

Motion indicates functionality / Motion clarifies the results of actions/ Motion conveys information.

\section{FOCUSING ATTENTION}

Motion focuses user attention / Motion emphasizes important elements of the interface.

REVEALING THE STRUCTURE

Motion reveals interface structure / Motion indicates relationships between elements.

INTERACTION PROCESS

Motion guides users during navigation / Motion indicates which gesture to perform next.

PROVIDING FEEDBACK

Motion provides feedback / Motion indicates change of state / Motion conveys status.

\section{LEARNING}

Motion provides guidance / Motion for teaching.

REFLECTING A STYLE

Motion reflects a particular style / Motion reflects a particular brand's style.

CONVEYING EMOTIONS

Motion conveys a particular emotion 
classification. In this way, Nielsen describes several functions in his guidelines for the use of multimedia elements online (Nielsen, 1995), Shneiderman et al. (2018) list a selection of roles present in Chevalier et al.'s taxonomy (2016), and Saffer (2013) collects a list of possible uses cited by Bill Scott, a professional in the sector, on his website.

The topic of interface animation and its influence on usability is not only discussed in academic literature but is also a recurring theme in blogs. The main sources in this regard are generally various developer design guidelines and the authors' professional experience. It is common for authors to include in their definition of functional animation a list of the possible roles that animation can play in an interface. The term has even begun to appear in brand design guidelines, such as that of Audi, where an entire section is devoted to functional animation:

Functional animations perform various functions in the interface: they guide the user through a process, improve orientation and provide feedback on entries. They supplement the interaction with small details which improve usability as well as being fun and offering emotional appeal. As such they are very important for a high-quality, fascinating, and brand-based user experience. (Audi, n.d.).
However, this media attention and the ubiquity of the use of animation are hardly reflected in the less abundant academic studies (Biørn-Hansen et al., 2019). Some of the most notable trends include research related to branding ( $\mathrm{Wu}$ et al., 2019), engagement (W. Li et al., 2020; Wu et al., 2020), and other aspects related to emotion and expressiveness (Fang et al., 2019; Ma et al., 2018; Thompson et al., 2020).

Among nonacademic publications, we would like to highlight the work of Rachel Nabors (2017) and Valery Head (2016), two professionals who specialized in animation. Nabors refers to a series of common use patterns in applications and web pages, such as transitions, supplements (fragments of information added to a page's content), feedback, demonstrations, and decorations (purely esthetic use, lacking information). Similarly, Head offers her own classification that includes several categories we identified within the work of Baecker and Small (e.g., the use of animation to guide and provide context, offer feedback, or demonstrate something), as well as other concepts described in design guidelines (e.g., focusing attention or expressing brand values through animation). The professionals who contribute via blog entries do not apply any specific methodologies to define their classification categories, as they are based on their expertise.

Figure 11. Language functions in the Jakobson communication model

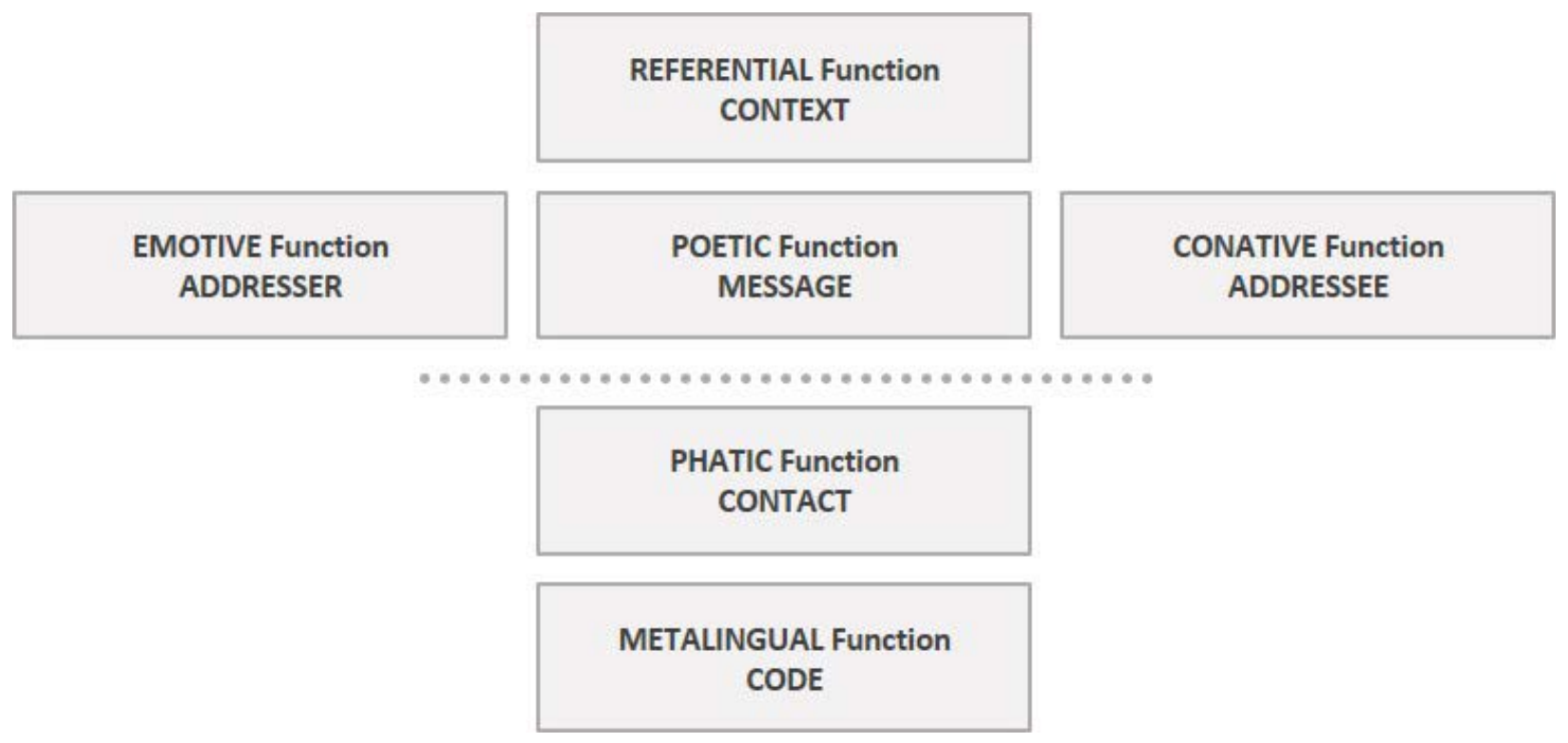

Note. Figure adapted from the schemes presented by Jakobson, R. (1984). Lingüística y poética. In Ensayos de lingüística general (pp. 347-395). Ariel. 


\section{Thematic Analysis of Design Guidelines}

To focus specifically on the practical uses of animation, we conducted a content analysis of the design guidelines of the main mobile phone operating systems: Apple iOS and Android.

As mentioned above, Liddle (2016) observed the tendency to prefer using the terms "motion" and "movement" when referring to animation in the design guidelines. We proceed to locate these terms and similar ones as "transition" and "dynamic," in addition to the term "animation," in order to carry out a comprehensive review of the guides. To obtain an overview, we create a list of phrases that refer to the roles of animation in the interface. We include sentences that refer to the use of animation explicitly and also implicit allusions that refer to all kinds of changes in the appearance of graphic elements over time. Once the initial list was made, we reformulated the statements in order to achieve a consistent and abbreviated format. This is the same procedure used by Nielsen in 1994 when he extracted his set of heuristics from seven sets of principles established by other authors (Nielsen, 1994, p. 156). Thus, the concepts expressed in the guides are synthesized, so that phrases such as "Transitions connect animated icons between two visual states" and "Transitions are used to toggle between icons, such as between on and off states" are reformulated with the same statement: "Motion indicates a change of state." We try to use, as far as possible, statements present in the guides themselves. In this way, we reduce the 96 phrases extracted from the Android guides and the 36 phrases from iOS to 18 statements that could be included in the eight thematic blocks collected in Figure 10.

\section{Proposal and Elaboration of a New Functional Animation Taxonomy}

\section{The Jakobson Model and Designer-User Communication}

One of the most influential models in communication theory was developed by mathematician Claude Shannon (Pelayo \& Cabrera, 2001) in his work for the Bell Telephone Laboratories (Shannon, 1948). His model does not attempt to describe the process of communication between humans, but rather the effectiveness of message transmission from an engineering point of view. The opposite position thus be- comes valid when taking inspiration from theories of human communication for the analysis of human-computer interaction. In Shannon's model, the semantic elements are irrelevant (Shannon \& Weaver, 1963, p. 3). Instead, we take Jakobson's work as a reference. Jakobson's proposal focuses on the functions of language and his text, Linguistics and Poetics (Jakobson, 1960), was prepared specifically for a conference held at the Massachusetts Institute of Technology (MIT), one of the leading research and development centers in the field of human-computer interaction.

\section{Functions in Jakobson's Communication Model}

Jakobson frames his proposal within semiotics, considering poetic features and all types of language as part of the general theory of signs (Jakobson, 1984, p. 349). It begins with the emotive, conative, and referential functions of the traditional Bühler model (Jakobson, 1984, p. 355) and refers to Malinowski when citing the phatic function. The model's structure is defined by the following six factors of verbal communication: addresser, contact, code, message, context, and addressee, each of which determines a different language function.

The referential, denotative, or cognitive function aims to identify, represent, or inform the context. The emotive or expressive function refers to the speaker's attitude towards the chosen topic, aiming to convey emotions. The conative function in imperative sentences is intended to convince or persuade the addressee. The phatic function, focused on contact, is found within messages that capture interlocutor's attention, confirming that their attention is held and that the communication channel is operating. The metalingual function is established when the sender or addressee seeks to confirm a code, such as when an explanation is added to clarify a complex text. Finally, the poetic function is oriented towards the message itself, for example, when a specific word is chosen instead of another but without affecting the meaning of the message.

\section{Connections to Design Principles and Guidelines}

Shneiderman et al. (2018) recall McLuhan's famous phrase - "the medium is the message" - to illustrate the idea that each user interface is a message from the designer to the user (p. 588). Despite this, the authors point out how, contrary to common belief, human-human interaction is not necessarily an appropriate model to understand how people interact with computers (p. 325). Even if human-human communica- 
tion models are not applicable to human-computer interaction, it seems valid to take them as a starting point for a semiotic perspective, with the understanding that, in human-computer interaction, communication always occurs between the human designer and human recipient (i.e., the user).

There are some explicit connections between Jakobson's statements and several of the key concepts reflected in the principles of interaction, usability, and interface design. For example, the phatic function (which exists in messages verifying the successful operation of the communication channel) seems to describe "feedback." The referential function (which is focused on informing the user about the context,) reminds us of the principles of visibility and recognition (Norman \& Nielsen, 2010); these principles are fundamental for orientating the user and helping them create a mental model of the system (Norman, 2013, p. 26). The metalinguistic function in explanatory texts is reflected in the principles that assert the need to provide explanatory and didactic as- sistance to the user (Shneiderman et al., 2018). Beginning with the Jakobson model and relating it to the terms extracted from the design guidelines, we found multiple parallels, as shown in Figure 12.

Some of the connections are clear, such as the conative function and its reflection in the use of animation to attract attention. The icon animation of a telephone presented when we receive an incoming call seeks to capture the user's attention in the same way as imperative sentences do in verbal language: "answer the phone!" Whether the animation shows the evolution of a process, the state of the system, or user activity, the feedback is parallel to the phatic function: an animation indicates that the communication channel is still working. Each time we press a key on a virtual keyboard, causing it to stand out above the others, we reproduce the classic "yes ... ah ... now ... yes, yes, I understand ..." characteristics of a telephone conversation that lacks visual feedback. Through this small animation, the designer has planned to convey to the user that the system has correctly

Figure 12. Relationships between Jakobson's communication functions and design guidelines

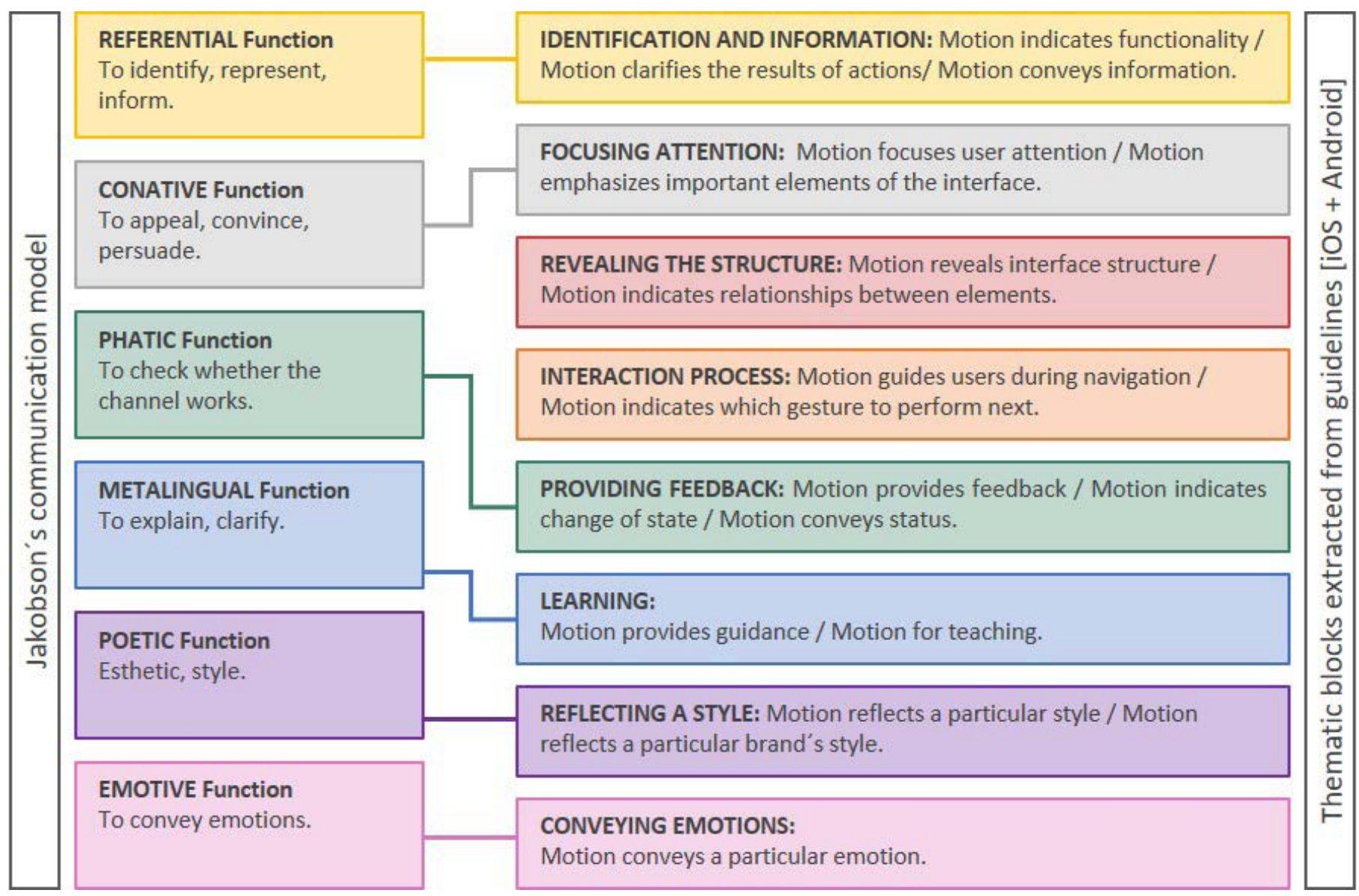


received their touch on the screen, and therefore their message.

One can thus describe the functions of animation in interface design with reference to Jakobson's model as follows:

- Referential function: the animation permits the identification of interface elements and their function.

- Emotive function: the animation represents and conveys emotions.

- Conative function: the animation attracts the user's attention.

- Phatic function: the animation keeps the user informed of the progress of an operation or the status of an application, providing feedback on the operation of the system and the user input.

- Metalinguistic (or Metalingual) function: the animation of the interface elements explains how to use the interface itself.

- Poetic function: the animation provides specific esthetic value to the system interface.

Two concepts that do not clearly match any of the categories in the Jakobson model can be extracted from the the- matic blocks of the guidelines: a) the use of animation to reveal the structure of the interface, highlighting the mental model that the user creates, and b) indications of interaction processes. These concepts can be found included in various functions described in the Jakobson model, but their functional parallels are not obvious. On the one hand, the importance of these two functions emphasizes the need for a different model in interface design; on the other hand, this also demonstrates the flexibility of the approach, as only six functions are required to cover the majority of the representative functions of animation in an interface.

Next, we look for parallels between the ten functions of Baecker et al. (1991) and the thematic blocks extracted from the guidelines. The objective here is to detect possible shortcomings in the taxonomy of Baecker et al. in the post-WIMP paradigm and to confirm the validity of its terminology.

\section{Baecker et al. Versus Design Guidelines}

In Figure 13, a color is assigned to each thematic block extracted from the design guidelines, and the related thematic blocks are indicated to the right of the categories of Baecker

Figure 13. Relationships between design guidelines and Baecker et al.'s taxonomy

\begin{tabular}{|l|}
\hline \multicolumn{1}{|c|}{ Guidelines [iOS + Android] } \\
\hline $\begin{array}{l}\text { IDENTIFICATION AND } \\
\text { INFORMATION }\end{array}$ \\
\hline FOCUSING ATTENTION \\
\hline REVEALING THE STRUCTURE \\
\hline INTERACTION PROCESS \\
\hline PROVIDING FEEDBACK \\
\hline LEARNING \\
\hline REFLECTING A STYLE \\
\hline
\end{tabular}

\begin{tabular}{|l|l|l|l|l|l|l|l|l|}
\hline \multicolumn{5}{|c|}{ Baecker et al. taxonomy [1991] } \\
\hline IDENTIFICATION: What is this? & & & & & & & \\
\hline TRANSITION: Where have I come from and gone to? & & & & & & & \\
\hline ORIENTATION: Where am I? & & & - & & & & & \\
\hline CHOICE: What can I do now? & & & & & & & & \\
\hline DEMONSTRATION: What can I do with this? & & & & & & & \\
\hline EXPLANATION: How do I do this? & & & & & & & \\
\hline FEEDBACK: What is happening? & & & & & & & & \\
\hline HISTORY: What have I done? & & & & & & & & \\
\hline INTERPRETATION: Why did that happen?
\end{tabular}

Note. A color code is assigned to each thematic block extracted from the design guidelines to show the connections with the categories of Baecker et al.'s (1991) taxonomy. 
et al.'s (1991) taxonomy. Eventually, a category could be equally related to more than one thematic block. For example, the "Transition" role corresponds to the structure that organizes content while helping the user during the interaction process, focusing their attention on the new content appearing on the screen. When a category could be included in several thematic blocks but one of them fits more clearly based on the descriptions found in the guidelines, we indicate only the latter to synthesize the information.

The absence of the "Orientation" and "Interpretation" categories from the initial taxonomy of Baecker and Small (1990) is indicated by a dotted line.

\section{Missing Categories}

We notice the absence of functions relating to the thematic blocks of style and emotion. In a taxonomy of ten functions, it is surprising that two functions from Jakobson's six-function model are missing, especially in a model describing something as complex as human communication. This issue becomes even more shocking when considering the allusions to such esthetic goals, such as achieving more attractive, appealing, or enjoyable interfaces, that were presented in the seminal article from 1990. However, no specific category is established to represent these concepts. The only allusion to the transmission of emotions can be found in the "Guidance" category, in the use of animation to make error messages less "intimidating." That being said, the purpose of this category is not really to convey emotion but rather to make the message more understandable by helping the user to correct the error.

Secondly, we observe how the concept of "focusing attention" does not correspond to a category of its own in the taxonomy of Baecker et al., but rather is included in all the roles. Without being perceived by the user, no element of the interface can fulfill any function. To our view, in the case of animation, attracting attention is not a function in itself but rather a property of the animation. The goal of drawing attention to an interface element would be, in Baecker et al.'s terms, to guide the user, present an option, help identify an element, etc. Taking into account the heuristic principle of aesthetics and minimalist design (Nielsen, 1994) or the principle of moderation (Stasko, 1993), an animation that does not fulfill any function but instead only attracts attention, contributing little or nothing to the usability or user experience, should be eliminated from the interface, as it will unnecessarily interrupt user activity, as stated in Nielsen's guidelines for the application of multimedia online (1995).

\section{Rejected Categories}

We encountered difficulties when trying to link some of the functions proposed by Baecker et al. (1991) with the blocks from the guidelines, in particular, those of "History" and "Choice," which were both considered to be hypothetical in Baecker and Small's work (1990). The animation type "History" corresponds to a situation in which steps carried out during the navigation process are shown as playback. A1though Chevalier et al. include this role in their classification, none of the examples they provide correspond to mobile devices. In fact, they describe specific products, some of them clearly in a development phase. Animation as a "Choice" scenario describes the preview of all the possible selection options within a complex menu. In this case, Baecker and Small highlight that this was technologically feasible at the time, but that its effectiveness needed to be verified empirically. This use is not relevant for mobile device interfaces, where complex menus are avoided.

The "History" and "Choice" animation roles are not only rare, but, due to their approach, they can be disconcerting for the user since the interface elements present an animation that is not being caused by the user interaction. This may break the seventh of Shneiderman's eight golden rules of interface design, which recommends keeping the control of the system in the hands of the user (Shneiderman et al., 2018, p. 96). These very specific uses could also be included in other categories, as both of them describe situations in which animation demonstrates the structure of the interface and guides the user through an interaction process. Note that these two concepts coincide with two of the thematic blocks extracted from the design guidelines, thus we consider the "History" and "Choice" categories to be unnecessary.

\section{Category Regrouping}

The "Orientation" category was incorporated into the 1991 taxonomy without any justification. Its function is described by the same example used to illustrate the "Transition" role in the 1990 classification. Therefore, we do not find an adequate reason to include these two as independent categories. The presented example (an animation that guides the user to a new window appearing on the desktop) is also related to two thematic blocks found in the guides: revealing the structure and the visual representation of an interaction process. 
The "Interpretation" role was also incorporated in 1991. The authors do not define the category or present examples for this role, except when indicating the answer to the question: "Why did that happen?" Therefore, we cannot discern its particular contribution when compared with similar categories, such as the "Explanation" role or that of "Guidance," both of which are focused on learning.

As Baecker and Small describe it, the "Guidance" role has two elements. On the one hand, it involves learning (i.e., making the system's error and help messages more understandable); on the other hand, it refers to the use of animation to guide the user during navigation. This second aspect does not refer to a learning process but is related to decisionmaking during the interaction process.

Another role that may be misleading is "Demonstration." This could be understood as a didactic function, but Baecker and Small use it more in relation to the identification of interface elements and the recognition of their functionality. It does not, however, refer to an animation of a tutorial of a tool, as the name might imply.
The "Identification" category only represents startup animations, such as the maligned "intros" commonly used when installing an application. Such "intros," due to their specific characteristics, can perform all the possible functions foreseen in the taxonomy.

In short, the Baecker et al. (1991) taxonomy includes categories that can be discarded or regrouped, and, in general, the nomenclature is not entirely appropriate today. In the design guidelines, the concept of guiding the user is more associated with navigation than with the emission of errors by the system, and animation to identify an application or functionality is found in more than just the "intros." At this point, the only remaining task is to decide the terms we will use to name the detected functions.

\section{Categories in the New Functional Animation Taxonomy}

Although the Jakobson model includes all the functions in Baecker et al.'s taxonomy and is an inspiring starting point,

Figure 14. Cathegories in the proposed functional animation taxonomy (back to text)

\section{Proposed FUNCTIONAL ANIMATION TAXONOMY}

IDENTIFYING FUNCTION

The animation permits the identification of the elements in the interface and their function.

\section{STRUCTURAL FUNCTION}

The animation reveals the structure of the interface, helping the user to understand the architecture of the information and to form a mental model of the operation of the system.

\section{GUIDEANCE FUNCTION}

The animation guides and orients the navigation of the user, indicating where and how they should interact with the elements of the interface.

FEEDBACK FUNCTION
The animation updates the user regarding the state of the system and the progress of its operations,
including receipt of input from the user and entry devices.
including receipt of input from the user and entry devices.

\section{DIDACTIC FUNCTION \\ The animation provides guidance about the operation of the interface itself and the execution of} tasks.

ESTHETIC FUNCTION

The animation has esthetic or decorative value, providing visual coherence and helping to define the visual style of the application.

EMOTIVE FUNCTION

The animation represents and conveys emotions. 
the terminology used is far from the typical jargon of human-computer interaction. Similarly, the problems detected with Baecker et al.'s terms led us to look for other options that avoid possible conflicts while reflecting the terminology used in the design guidelines. The overall aim is to define a taxonomic tool that will be useful not only in research but also in professional and teaching practice.

In the elaboration of the taxonomy, we attempted to strike a balance between exhaustive and exclusive categories. We chose to classify general functions rather than focusing on all possible specific uses. Instead of using categories such as distinguishing "importance and urgency" (Novick et al., 2011) or to "convey uncertainty or randomness" (Chevalier et al., 2016), we decided to use broad categories that cover other, similar properties. For example, the concept of "delight" - introduced by Head (2016) - is included in the "Emotive" function, along with other concepts such as "hook the user" from Chevalier et al. Figure 14 presents the resulting proposal for the functions of animation in interface design.

\section{Identifying Function}

This type of animation permits the identification of elements in an interface and their function. An example would be the animations of the stopwatch, alarm, and timer icons in the Android "Clock" application (see Figure 15). Some of these icons are practically the same, but the animation helps to identify the function of each. In the "Stopwatch" icon, the clock hand makes a $360^{\circ}$ turn. The "Alarm" icon features an animation reminiscent of an old bell alarm clock. In the "Timer" app, the animation features sand falling after turning the hourglass.

\section{Structural Function}

When scrolling, some applications show a small bounce or an animated graphic that tells us when we have reached the end of the content, as shown in Figure 16. Through these

\section{Figure 15. Example of Identifying Function}

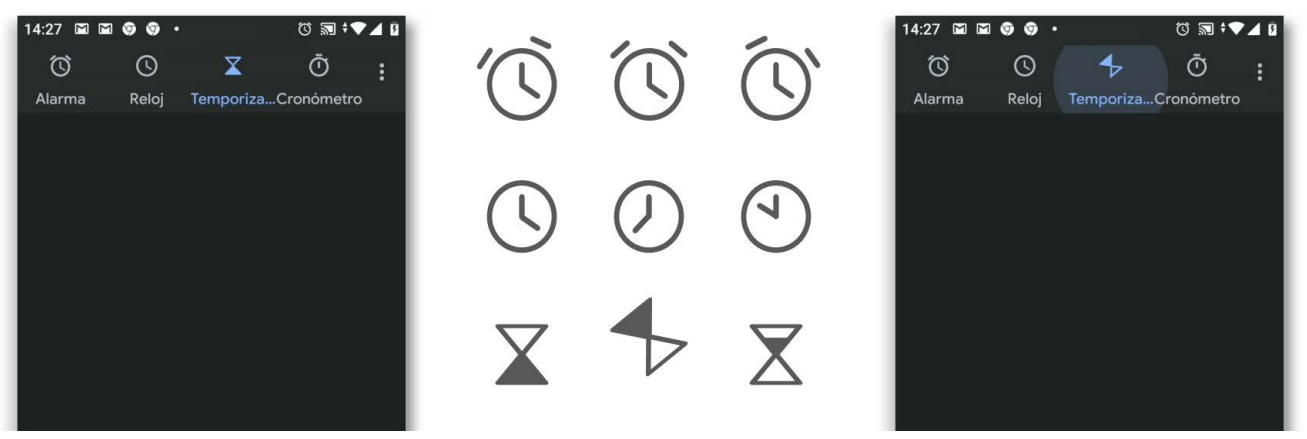

Note. Screenshot of WhatsApp (Version 2.21.4.22). An animated graphic indicates that the end of the content has been reached.

\section{Figure 16. Example of Structural Function}
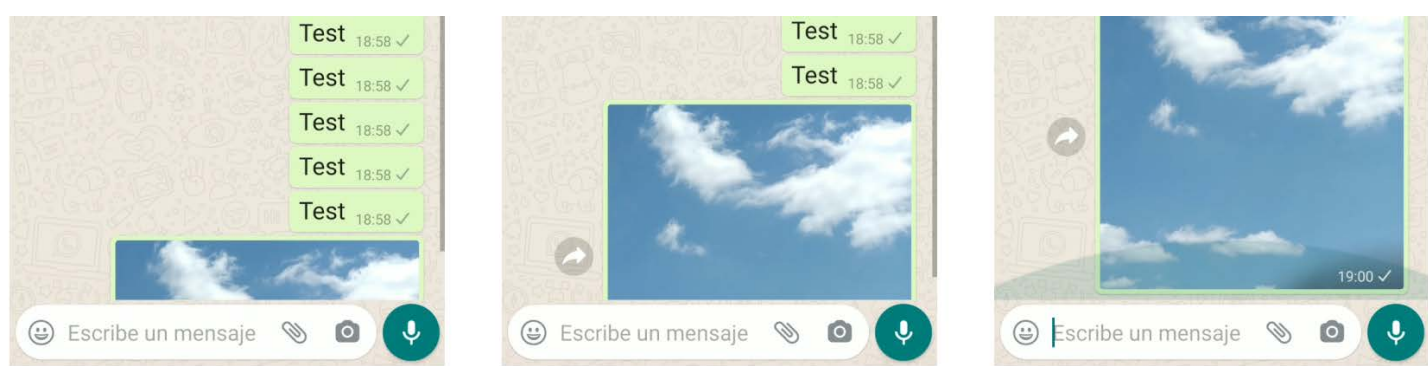

Note. Screen capture of Android Clock application (Version 6.2.1-280557501) and representations of the evolution of icons created by authors. 
effects, animation fulfills a structural function by highlighting the format of the interface, helping the user to understand the information architecture and create a mental model of the system.

\section{Guidance Function}

Such animations guide and orientate the user during navigation, indicating where or how to interact with the elements of the interface. For example, the animation of a graphical element expanding in a specific direction suggests that a drag gesture should be performed instead of a simple tap on the screen. This would be an example of "feedforward animation" (Vermeulen et al., 2013) that provides information about an action that can be made. Figure 17 shows an example of feedforward. Likewise, the animation of the elements may indicate the order of the steps to follow during an interaction, or indicate actions that require user intervention.

\section{Feedback Function}

Such animations keep the user informed about the status of the system or the progress of an operation, including responding to user input or other input devices. Perhaps this is one of the most obvious and relevant animation functions. We would hardly understand any interaction if the system did not present any change on the screen. Some clear examples of the feedback function include the animated progress indicators that show the status of a process (see Figure 18), the animation of keys increasing in size in response to user touches, or animations representing orientation data captured by the device's gyroscope.

\section{Didactic Function}

Such animations provide instructions on the operation of the interface itself and the execution of tasks, helping users achieve the goal for which they use an application.

This function may include tutorials that provide informa-

\section{Figure 17. Example of Guidance}
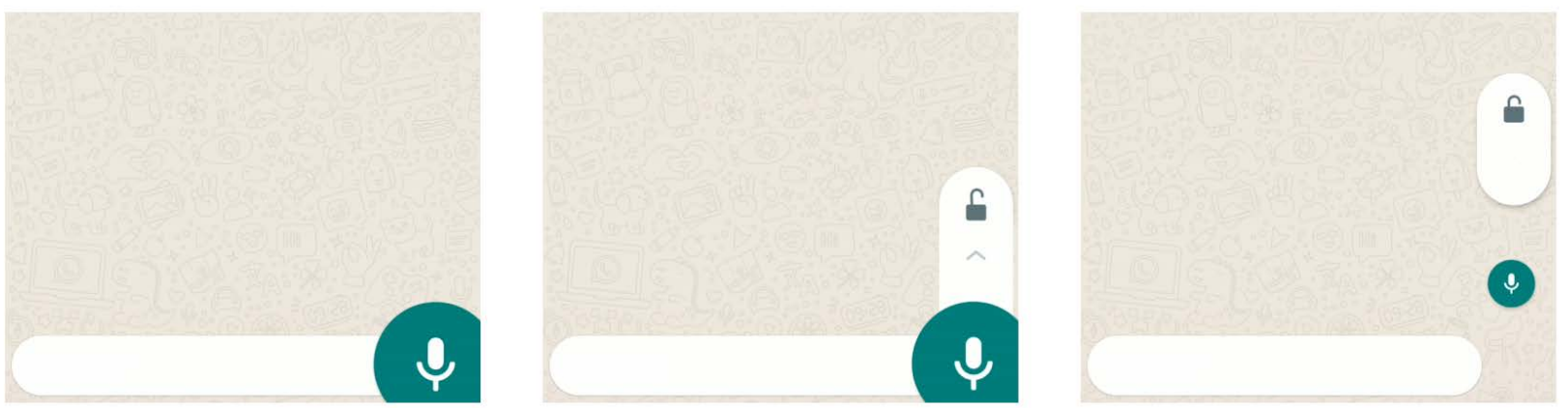

Note. Screenshot of WhatsApp (Version 2.19.291). The arrow and the animated graphic suggest the user to perform a drag gesture that will lock the screen while recording audio.

Figure 18. Example of Feedback
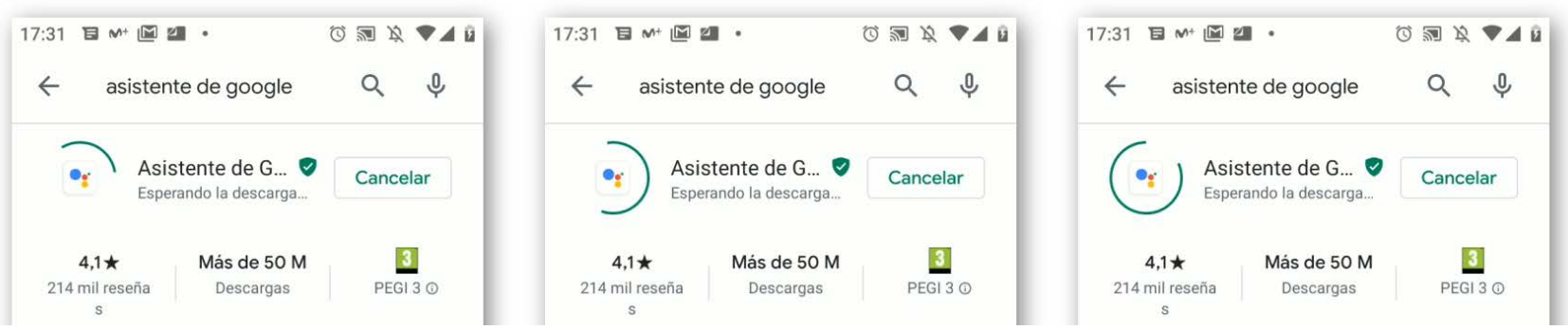

Note. Screenshot of an installation process showing a progress indicator in Android 9. 
tion on an app's operation, either during the loading process or within the application itself, as well as showing how to achieve objectives. For example, a physical exercise application may demonstrate how to perform crunches through illustrations and informational texts. But, by using an animation of a character performing the exercise as in the application "Seven," the user quickly grasps in detail the movements and rhythm to follow during training. A graphic can hardly provide such a precise instruction (see Figure 19). Therefore, animation design will help the users to more effectively reach their goal.

\section{Esthetic Function}

Such animations add esthetic or decorative value, provide visual coherence, and help define the visual style of an application. The possibilities are practically endless when de- signing a process indicator through animation. One can choose to use either the classic circular loading shape constantly rotating in a loop, or elements characteristic of the brand. For example, the Google Home application presents different versions of the loading indicator depending on the activity being carried out (e.g., detecting devices in the environment or connecting to a WIFI network, as shown in Figure 20), but it always uses the same visual codes: simple geometric shapes and the four characteristic brand colors (Gunner, n.d.). The importance of esthetic value should be considered, particularly to avoid the misunderstanding that an animation should be removed because it only performs a decorative function. Empirical studies by Kurosu and Kashimura (1995), Tractinsky (1997), and Tractinsky et al. (2000) have shown that, when faced with two identically functioning systems that only differ in terms of their esthet-

Figure 19. Example of Didactic Function
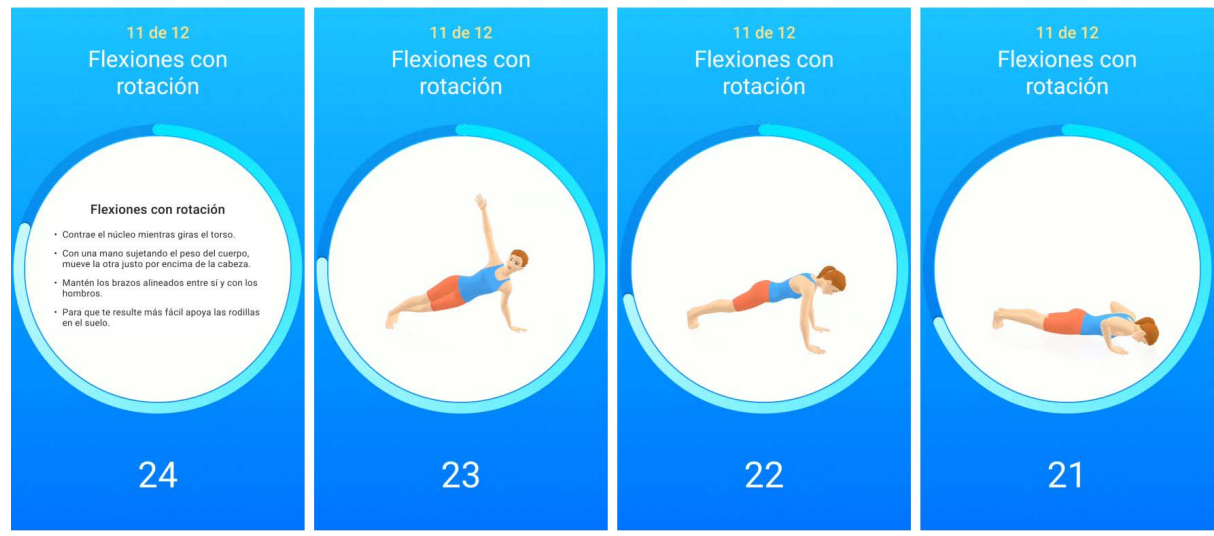

Note. Screenshots of "Seven", training application (Version 9.8.1). The first image is a recreation created by the authors to show how the interface would look like if no animation were included.

\section{Figure 20. Example of Esthetic Function}

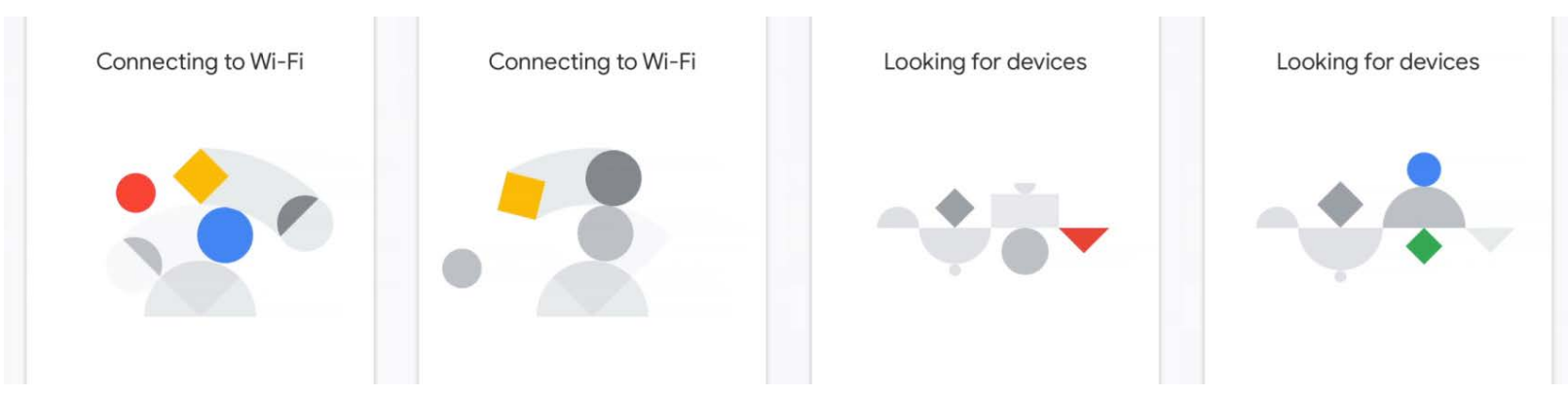

Note. Progress indicators for Google Home application by Gunner. (n.d.). Google Home App. Retrieved October 9, 2020, from https:// www.gunner.work/googlehome 
Figure 21. Example of Emotive Function.
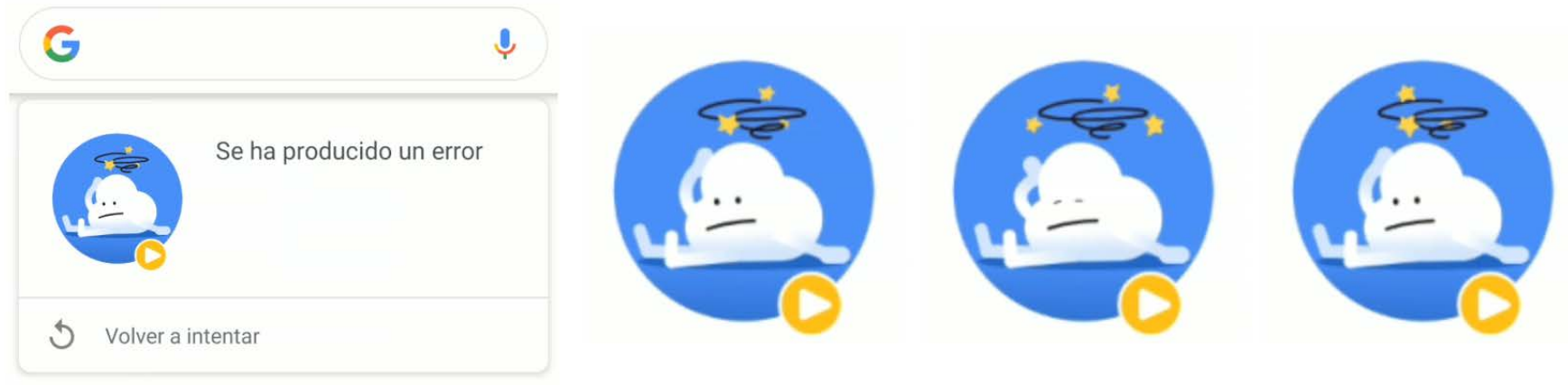

Note. Screenshot of an error message on Google Chrome (Version 81.0.4044.138).

ics, subjects are not only attracted by the more visually pleasing system but also found it easier to use. Therefore, the esthetics affects the usability of a system: "attractive things work better" (Norman, 2004, p. 17).

\section{Emotive Function}

The animation of an element can represent and convey different sensations and emotional states. The appearance of a notification can make us feel the urgency or importance of a warning, as the speed and amplitude of the notification can prompt different degrees of tension or serenity. As shown in Figure 21, some applications show amusing little animations when a malfunction occurs, trying to empathize with our feelings of frustration at the system crashing or the incomprehensible error message that can appear, such as "Error 504: A command parameter is missing." Animation can therefore represent and convey emotions.

\section{Conclusions}

The current proposal begins from the functions in Baecker et al. (1991)'s taxonomy, which is completed by the inclusion of the two functions described in Jakobson's model, the iOS and Android guidelines, and other consulted taxonomies, namely, the "Esthetic" and "Emotive" functions. We subsequently discarded other previously proposed categories for being overspecific, unlikely, nonexistent, or at least inadvisable uses of animation on mobile devices. In the same way, some categories were regrouped, combining them with others included in leading design guidelines and representing the current most significant uses of animation. All this was achieved while maintaining the fundamentals of animation use, consistent with the principles of interaction and heuristics to identify the animation functions that can be beneficial, especially for improving usability and user experience. In this way, we developed a taxonomy by applying a formal method with the aim of creating a reference point for the range of taxonomies that offer a more personal and subjective point of view.

The decisions regarding the nomenclature of the functions required thorough consideration. Multiple possibilities arise when naming the animation functions that allow us to identify different elements of the interface and recognize their purpose: referential, denotative, cognitive, informative, descriptive, interpretive, designative, etc. When choosing the terms, we tried to avoid names that could be associated with more than one function, such as "orientative," which could illustrate both guiding as well as a didactic or even structural function, as it consistently refers to guiding the user through the structure of the system.

Innovation in the mobile device sector is mainly driven by private companies involved in an endless commercial race to offer consumers increasingly more attractive products. Therefore, it remains possible that the most recent animation applications may not be considered within the design guidelines since they are still in the development phase. For this reason, we considered it appropriate to expand this review by consulting also non-academic sources that can provide information on the most innovative uses of animation in interface design. We will therefore validate our taxonomy after further analysis of different sources that may reveal 
other animation functions not considered herein.

Classification tasks are always complex and liable to yield several possible configurations. The current proposal seeks to establish broad categories capable of accommodating multiple, specific categories that could be further defined in the future. For example, within "feedback," as suggested by the category description, one could add user input, indicate the state of the system, represent the evolution of a specific process, or demonstrate the input of a device's sensors.

The rule of having exhaustive and exclusive categories is closer to the realm of ideas than to the real field of practice. What matters is to know to what degree this new taxonomy addresses our original objective: to detect whether an animation fulfills its function in an interface. Our classification aims to act as a tool to detect superfluous animations that contribute little or nothing to the user experience, unnecessarily consume resources in their preparation and implementation, and add to the potential for negative effects on the system's usability.
The validation process will be based on a selection of real design cases from the industry that represent a clear example of each category. Validating the taxonomy will not only confirm the extent to which a consensus among experts is reached regarding the adequacy of the terminology used, but also enable its validation as a useful tool in the teaching field to help detect, classify, and assess the appropriateness of an animation based on its potential roles in an interface. For example, during a practical exercise in which students are asked to develop animations for the user interface of an application, the teacher can ask them to analyze their designs using the taxonomy as a guide. Each one of their animations should be clearly included in at least one of the categories; if not, the students should reconsider their proposal.

This taxonomy may also form the basis for developing a heuristic assessment tool, or the development of an inspection manual to guide decision-making during prototype design. 


\section{References}

Apple Computer, I. (1987). Human Interface Guidelines: The Apple Desktop Interface. Addison Wesley Publishing Company, Inc. http://archive.org/details/applehumaninterf00appl

Apple Inc. (n.d.). Themes-IOS - Human Interface Guidelines-Apple Developer. Retrieved April 9, 2021, from

https://developer.apple.com/design/human-interface-guidelines/ios/overview/themes/\#//apple_ref/doc/uid/TP40006556CH57-SW1

Audi. (n.d.). User Interface / UI Animation / Functional Animation. Retrieved October 7, 2020, from https://www.audi.com/ ci/en/guides/user-interface/ui-animation/functional-animation.html

Avila-Muñoz, R., Clemente-Mediavilla, J., \& Pérez Luque-Maricalva, M. J. (2019). Hacia una taxonomía de las funciones de la animación en la interfaz de usuario. Contenidos audiovisuales, narrativas y alfabetización mediática, 2019, ISBN 978-84-486-1816-2, págs. 557-567, 557-567. https://dialnet.unirioja.es/servlet/articulo?codigo=6950103

Baecker, R. (1998). Sorting Out Sorting: A Case Study of Software Visualization for Teaching Computer Science. In Software visualization: Programming as a multimedia experience (pp. 369-381). MIT Press. http://archive.org/details/ softwarevisualiz0000unse

Baecker, R. (2002). Showing instead of telling. Proceedings of the 20th Annual International Conference on Computer Documentation, 10-16. https://doi.org/10.1145/584955.584957

Baecker, R., \& Small, I. (1990). Animation at the Interface. In B. Laurel \& S. J. Mountford (Eds.), The Art of Human-Computer Interface Design (pp. 251-267). Addison-Wesley Publishing Co., Inc.

Baecker, R., Small, I., \& Mander, R. (1991). Bringing icons to life. Proceedings of the SIGCHI Conference on Human Factors in Computing Systems, 1-6. https://doi.org/10.1145/108844.108845

Baek, Y. K., \& Layne, B. H. (1988). Color, graphics, and animation in a computer-assisted learning tutorial lesson. Journal of Computer-Based Instruction, 15(4), 131-135.

Bartram, L. (1997a). Perceptual and Interpretative Properties of Motion for Information Visualization (Technical Report CMPT-TR:1997-15; p. 35). Simon Fraser University. https://www.researchgate.net/publication/221615053_Perceptual_ and_Interpretative_Properties_of_Motion_for_Information_Visualization

Bartram, L. (2001). Enhancing Information Visualization with Motion [Doctoral dissertation, Simon Fraser University]. https://citeseerx.ist.psu.edu/viewdoc/download?doi=10.1.1.21.5486\&rep=rep1\&type=pdf

Bartram, L. (1997b). Perceptual and interpretative properties of motion for information visualization. Proceedings of the 1997 Workshop on New Paradigms in Information Visualization and Manipulation, 3-7. https://doi.org/10.1145/275519.275520

Bartram, L., Ware, C., \& Calvert, T. (2003). Moticons: Detection, distraction and task. International Journal of Human-Computer Studies, 58(5), 515-545. https://doi.org/10.1016/S1071-5819(03)00021-1

Bétrancourt, M., \& Tversky, B. (2000). Effect of computer animation on users' performance: A review. Le Travail Humain: A Bilingual and Multi-Disciplinary Journal in Human Factors, 63(4), 311-329.

Biørn-Hansen, A., Grønli, T.-M., \& Ghinea, G. (2019). Animations in Cross-Platform Mobile Applications: An Evaluation of Tools, Metrics and Performance. Sensors, 19(9), 2081. https://doi.org/10.3390/s19092081

Chalbi, A. (2018). Understanding and designing animations in the user interfaces [Doctoral dissertation, Universite lille1]. tel01881889. https://hal.archives-ouvertes.fr/tel-01881889/

Chang, B.-W., \& Ungar, D. (1993). Animation: From cartoons to the user interface. Proceedings of the 6th Annual ACM Symposium on User Interface Software and Technology, 45-55. https://doi.org/10.1145/168642.168647

Chevalier, F., Riche, N. H., Plaisant, C., Chalbi, A., \& Hurter, C. (2016). Animations 25 Years Later: New Roles and Opportunities. Proceedings of the International Working Conference on Advanced Visual Interfaces, 280-287. https://doi.org/10.1145/2909132.2909255

de la Torre - Arenas, I., \& Cruz, P. (2017). A taxonomy of motion applications in data visualization. Proceedings of the Symposium on Computational Aesthetics, 1-2. https://doi.org/10.1145/3092912.3122798

de Souza, C. S., Leitão, C. F., Prates, R. O., Amélia Bim, S., \& da Silva, E. J. (2010). Can inspection methods generate valid 
new knowledge in HCI? The case of semiotic inspection. International Journal of Human-Computer Studies, 68(1), 22-40. https://doi.org/10.1016/j.ijhcs.2009.08.006

Djajadiningrat, T., Geurts, L., Munniksma, P. R., Christiaansen, G., \& de Bont, J. (2009). Rationalizer: An emotion mirror for online traders. Proceedings of the Conference on Design and Semantics of Form and Movement - DeSForM 2009, 39-48.

Fang, Y.-M., Chun, L., \& Chu, B.-C. (2019). Older Adults' Usability and Emotional Reactions toward Text, Diagram, Image, and Animation Interfaces for Displaying Health Information. Applied Sciences, 9(6), 1058. https://doi.org/10.3390/app9061058

Fisher, D. (2010). Animation for Visualization: Opportunities and Drawbacks. In Beautiful Visualization (pp. 329-352). O'Reilly Media Inc.

Froehlich. (2010). Motion for Interface: A Taxonomy [Masters in Fine Art Thesis]. Dynamic Media Institute at Massachusetts College of Art and Design.

Froehlich, E. (2018). Motion Attracts Attention. In R. B. Stone \& L. Wahlin (Eds.), The Theory and Practice of Motion Design: Critical Perspectives and Professional Practice (pp. 114-126). Routledge.

Froehlich, E., Lucid, B., \& Shaw, H. (2013). The language of motion: A taxonomy for interface. In M. Kurosu (Ed.), Proceedings of the 15th international conference on Human-Computer Interaction: Interaction modalities and techniques: Vol. IV (pp. 668-677). Springer-Verlag. https://doi.org/10.1007/978-3-642-39330-3_72

Gonzalez, C. (1996). Does animation in user interfaces improve decision making? Proceedings of the SIGCHI Conference on Human Factors in Computing Systems, 27-34. https://doi.org/10.1145/238386.238396

Google. (n.d.). material.io-Understanding motion. Material Design. Retrieved June 14, 2018, from https://material.io/ design/motion/understanding-motion.html\#principles

Gunner. (n.d.). Google Home App. Retrieved October 9, 2020, from https://www.gunner.work/googlehome

Han, P. K. J., Klein, W. M. P., Killam, B., Lehman, T., Massett, H., \& Freedman, A. N. (2012). Representing randomness in the communication of individualized cancer risk estimates: Effects on cancer risk perceptions, worry, and subjective uncertainty about risk. Patient Education and Counseling, 86(1), 106-113. https://doi.org/10.1016/j.pec.2011.01.033

Harrington, T. L., Bidyuk, P. I., \& Harrington, M. K. (1994). Motion as a Variable of Visual Communication. In Human-Machine Communication for Educational Systems Design (pp. 17-24). Springer Berlin Heidelberg.

Head, V. (2016). Designing Interface Animation. Rosenfeld Media. https://rosenfeldmedia.com/books/designing-interfaceanimation/

Heer, J., \& Robertson, G. (2007). Animated Transitions in Statistical Data Graphics. IEEE Transactions on Visualization and Computer Graphics, 13(6), 1240-1247. https://doi.org/10.1109/TVCG.2007.70539

Heer, J., \& Shneiderman, B. (2012). Interactive Dynamics for Visual Analysis. Queue, 10(2), 30-55. https://doi.org/10.1145/2133416.2146416

Jakobson, R. (1960). Linguistics and Poetics. In T. A. Sebeok (Ed.), Style in Language (pp. 350-377). The MIT Press. http://archive.org/details/styleinlanguage00confrich

Jakobson, R. (1984). Lingüística y poética. In Ensayos de lingüistica general (pp. 347-395). Ariel.

Kurosu, M., \& Kashimura, K. (1995). Apparent usability vs. inherent usability: Experimental analysis on the determinants of the apparent usability. Conference Companion on Human Factors in Computing Systems, 292-293. https://doi.org/10.1145/223355.223680

Li, W., Wang, Y., Zhang, H., \& Qu, H. (2020). Improving Engagement of Animated Visualization with Visual Foreshadowing. ArXiv:2009.03784 [CS]. http://arxiv.org/abs/2009.03784

Li, Y., You, F., Ji, M., \& You, X. (2020). The Influence of Smartphone Text Input Method, Posture, and Environment on User Experience. International Journal of Human-Computer Interaction, 36(12), 1110-1121. https://doi.org/10.1080/10447318.2020.1719465

Liddle, D. (2016). Emerging Guidelines for Communicating with Animation in Mobile User Interfaces. Proceedings of the 34th ACM International Conference on the Design of Communication, 1-9. https://doi.org/10.1145/2987592.2987614

López-Jaquero, V. M., González, P., Montero, F., \& Molina, J. P. (2020). UML2App: Avanzando en la generación automática de interfaces de usuario para dispositivos móviles. Revista de la Asociación Interacción Persona Ordenador (AIPO), 1, 9-21. 
Loranger, H., Schade, A., \& Nielsen, J. (2013). Website Tools and Applications with Flash. https://www.nngroup.com/reports/ website-tools-and-applications-flash/

Ma, J., Chen, C.-C., \& Lin, Y.-C. (2018). Emotional and Cognitive Assessment of Use of Functional Animation. Proceedings of the International Conference on Machine Vision and Applications, 61-65. https://doi.org/10.1145/3220511.3220516

Marshall, J., Dancu, A., \& Mueller, F. "Floyd." (2016). Interaction in Motion: Designing Truly Mobile Interaction. Proceedings of the 2016 ACM Conference on Designing Interactive Systems, 215-228. https://doi.org/10.1145/2901790.2901844

Myers, B. A. (1984). The user interface for Sapphire. IEEE Computer Graphics and Applications, 4(12), 13-23. https://doi.org/10.1109/MCG.1984.6429376

Myers, B. A. (1985). The importance of percent-done progress indicators for computer-human interfaces. ACM SIGCHI Bulletin, 16, 11-17. https://doi.org/10.1145/317456.317459

Nabors, R. (2017). Animation at Work. A Book Apart.

Nicol, A. (1990). Interfaces for Learning: What Do Good Teachers Know That We Don't? In B. Laurel (Ed.), The art of human- computer interface design (pp. 251-267). Addison-Wesley.

Nielsen, J. (1995). Guidelines for Multimedia on the Web. Nielsen Norman Group - Articles. https://www.nngroup.com/articles/ guidelines-for-multimedia-on-the-web/

Nielsen, J. (2005). Top 10 Web Design Mistakes of 2005. Nielsen Norman Group - Articles. https://www.nngroup.com/articles/ top-ten-web-design-mistakes-of-2005/

Nielsen, J. (1994). Enhancing the explanatory power of usability heuristics. Proceedings of the SIGCHI Conference on Human Factors in Computing Systems, 152-158. https://doi.org/10.1145/191666.191729

Norman, D. A. (2004). Emotional design: Why we love (or hate) everyday things. Basic Books.

Norman, D. A. (2013). The design of everyday things (Revised and expanded edition). Basic Books.

Norman, D. A., \& Nielsen, J. (2010). Gestural interfaces: A step backward in usability. Interactions, 17(5), 46-49. https://doi.org/10.1145/1836216.1836228

Novick, D., Rhodes, J., \& Wert, W. (2011). The communicative functions of animation in user interfaces. Proceedings of the 29th ACM International Conference on Design of Communication, 1-8. https://doi.org/10.1145/2038476.2038478

Parhi, P., Karlson, A. K., \& Bederson, B. B. (2006). Target size study for one-handed thumb use on small touchscreen devices. Proceedings of the 8th Conference on Human-Computer Interaction with Mobile Devices and Services, 203-210. https://doi.org/10.1145/1152215.1152260

Pelayo, N., \& Cabrera, A. (2001). Lenguaje y comunicación: Conceptos básicos, aspectos teóricos generales, características, estructura, naturaleza y funciones del lenguaje y la comunicación oral y escrita. El Nacional.

Rheinfrank, J., \& Evenson, S. (1996). Design Languages. In T. Winograd (Ed.), Bringing Design to Software (pp. 63-85). Addison Wesley Publishing Company, Inc. https://doi.org/10.1145/229868.230034

Saffer, D. (2013). Microinteractions. O'Reilly Media, Inc.

Scolari, C. (2018). Las leyes de la interfaz: Diseño, ecología, evolución, tecnología. Gedisa.

Shannon, C. E. (1948). A Mathematical Theory of Communication. The Bell System Technical Journal, 27(3), 379-423.

Shannon, C. E., \& Weaver, W. (1963). The mathematical theory of communication. Urbana: University of Illinois Press.

http://archive.org/details/mathematicaltheo00shan

Shneiderman, B. (1987). Designing the User Interface: Strategies for Effective Human-computer Interaction. Addison Wesley Publishing Company, Inc.

Shneiderman, B., Plaisant, C., Cohen, M., Jacobs, S., Elmqvist, N., \& Diakopoulos, N. (2018). Designing the User Interface: Strategies for Effective Human-Computer Interaction, Global Edition (6th edition). Pearson Education Limited.

shodan1138. (2015, May 3). GIGUW \#2-Robot Odyssey. https://www.youtube.com/watch?v=h6Ceo2hPuPI\&t=228s

Spallazzo, D., Sciannamè, M., \& Ceconello. (2019). The Domestic Shape of AI: A Reflection on Virtual Assistants. Proceedings of the Conference on Design and Semantics of Form and Movement - DeSForM 2019, 52-59.

Stasko, J. T. (1993). Animation in user interfaces: Principles and techniques. In L. Bass \& P. Dewan (Eds.), User Interface Software (pp. 81-101). John Wiley \& Sons, Inc. 
Stasko, J. T. (1990). A practical animation language for software development. Proceedings. 1990 International Conference on Computer Languages, 1-10. https://doi.org/10.1109/ICCL.1990.63755

Thompson, J., Liu, Z., \& Stasko, J. (2020). Understanding the Design Space and Authoring Paradigms for Animated Data Graphics. Computer Graphics Forum, 39(3), 207-218. https://doi.org/10.1111/cgf.13974

Tractinsky, N, Katz, A. S., \& Ikar, D. (2000). What is beautiful is usable. Interacting with Computers, 13(2), 127-145. https://doi.org/10.1016/S0953-5438(00)00031-X

Tractinsky, Noam. (1997). Aesthetics and apparent usability: Empirically assessing cultural and methodological issues. Proceedings of the ACM SIGCHI Conference on Human Factors in Computing Systems, 115-122. https://doi.org/10.1145/258549.258626 Vermeulen, J., Luyten, K., van den Hoven, E., \& Coninx, K. (2013). Crossing the bridge over Norman's Gulf of Execution: Revealing feedforward's true identity. Proceedings of the SIGCHI Conference on Human Factors in Computing Systems, 1931-1940. https://doi.org/10.1145/2470654.2466255

Walker, J. (1990). Through the looking glass. In B. Laurel \& S. J. Mountford (Eds.), The Art of Human-Computer Interface Design (pp. 439-448). Addison-Wesley Publishing Co., Inc.

Ware, C. (2020). Information Visualization: Perception for Design (4a). Morgan Kaufmann. https://doi.org/10.1016/C2016-0-02395-1

Wasserman, A. I. (2010). Software engineering issues for mobile application development. Proceedings of the FSE/SDP Workshop on Future of Software Engineering Research, 397-400. https://doi.org/10.1145/1882362.1882443

Weiss, R. E., Knowlton, D. S., \& Morrison, G. R. (2002). Principles for using animation in computer-based instruction: Theoretical heuristics for effective design. Computers in Human Behavior, 18(4), 465-477.

https://doi.org/10.1016/S0747-5632(01)00049-8

Wigdor, D., \& Wixon, D. (2011). Brave NUI World: Designing Natural User Interfaces for Touch and Gesture (1st ed.). Morgan Kaufmann Publishers Inc.

Wroblewski, L. (2011). Mobile First. A book Apart.

Wu, Z., Jiang, Y., Liu, Y., \& Ma, X. (2020). Predicting and Diagnosing User Engagement with Mobile UI Animation via a Data-Driven Approach. Proceedings of the 2020 CHI Conference on Human Factors in Computing Systems, 1-13. https://doi.org/10.1145/3313831.3376324

Wu, Z., Kim, T., Li, Q., \& Ma, X. (2019). Understanding and Modeling User-Perceived Brand Personality from Mobile Application UIs. Proceedings of the 2019 CHI Conference on Human Factors in Computing Systems, 1-12. https://doi.org/10.1145/3290605.3300443 


\section{Copyrights and Repositories}

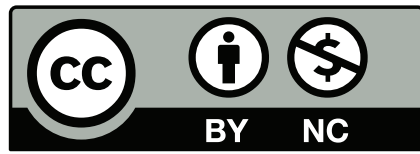

This work is licensed under the Creative Commons Attribution-NonCommercial-3.0 Unported License.

This license allows you to download this work and share it with others as long as you credit the author and the journal. You cannot use it commercially without the written permission of the author and the journal ("Review of Communication Research").

\section{Attribution}

You must attribute the work to the author and mention the journal with a full citation, whenever a fragment or the full text of this paper is being copied, distributed or made accessible publicly by any means.

\section{Commercial use}

The licensor permits others to copy, distribute, display, and perform the work for non-commercial purposes only, unless you get the written permission of the author and the journal.

The above rules are crucial and bound to the general license agreement that you can read at:

http://creativecommons.org/licenses/by-nc/3.0/

\section{Corresponding author}

Jorge Clemente Mediavilla

Complutense University of Madrid, Spain

jclemen@ucm.es

Attached is a list of permanent repositories where you can find the articles published by RCR:

Academia.edu@http://independent.academia.edu/ReviewofCommunicationResearch

Internet Archive@ http://archive.org (collection "community texts")

Social Science Open Access Repository, SSOAR @ https://www.ssoar.info/ssoar/ 